\title{
Study on Surrounding Rock Structure Evolution Characteristics and Roof Control Techniques of the Retained Roadway Formed by Roof Cutting in Inclined Coal Seams
}

\author{
Guangyuan Yu $\mathbb{D}^{1,2}$ Jiong Wang $\mathbb{D}^{1,2}$ Jianjun Ren, ${ }^{3}$ Jinzhu Hu $\mathbb{D}^{1,2}$ Zhifu Pan, ${ }^{1,2}$ \\ Delu Wang, ${ }^{1,2}$ and Wei Ming ${ }^{1,2}$ \\ ${ }^{1}$ State Key Laboratory of Geomechanics and Deep Underground Engineering, China University of Mining and Technology, \\ Beijing 100083, China \\ ${ }^{2}$ School of Mechanics and Civil Engineering, China University of Mining and Technology, Beijing 100083, China \\ ${ }^{3}$ College of Physics and Engineering, Xingyi Normal University for Nationalities, Xingyi 562400, China
}

Correspondence should be addressed to Jiong Wang; wangjiong0216@163.com and Jinzhu Hu; hujinzhu_cumtb@163.com

Received 27 May 2021; Accepted 16 June 2021; Published 28 June 2021

Academic Editor: Gan Feng

Copyright $\odot 2021$ Guangyuan Yu et al. This is an open access article distributed under the Creative Commons Attribution License, which permits unrestricted use, distribution, and reproduction in any medium, provided the original work is properly cited.

To control the roof during gob-side entry retaining by roof cutting in inclined coal seams, the retained gob-side roadway is zoned based on the mechanical principle and technological process of no-pillar mining with gob-entry retention. A simplified mechanical model for surrounding rocks in different subzones was established by using theoretical analysis and numerical simulation to attain the demand for the support resistance and deformation of the roof in different subzones. According to load and deformation characteristics of the roof and mechanical characteristics of NPR cables, single props, and a sliding-type gangueretaining structure formed by U-shaped steel inserts, the supporting systems for roadways in different subzones and the constitutive model thereof were established. On this basis, the action of the supporting system was analysed and a field test was performed. The results show that the supporting system undergoes three stages of behaviour, i.e., pressure growth, yielding under constant pressure, and stabilisation during whole entry retention. It can guarantee the collaborative deformation of the supporting systems with the roof on the premise of constant support resistance, thus satisfying the requirement for roadway protection. The roadway $150 \mathrm{~m}$ back from the working face is stable, and the final convergence between the roof and floor of the retained entry is $257 \mathrm{~mm}$, showing a favourable entry-retention effect.

\section{Introduction}

Coal is among the most important basic sources of energy, accounting for approximately $30 \%$ of global energy consumption $[1,2]$. China, as a large energy consumer, consumes coal in an amount sufficient to account for over $50 \%$ of all primary energy demand by $2030[3,4]$. Statistics show that about $55 \%$ of the recoverable coal reserves occur in inclined coal seams in China [5]. Therefore, safe and efficient exploitation of inclined coal seams is important when trying to relieve the pressure on the nation in terms of the demand for energy. At present, traditional longwall mining techniques are mostly used for mining inclined coal seams, which leads to the average mine recovery rate being only about $50 \%$, as many coal pillars acting as shields are left underground and cannot be reclaimed $[6,7]$. Therefore, it is necessary to develop no-pillar mining techniques for use in inclined coal seam to increase resource recovery.

The gob-side entry-retention technique based on pressure relief by roof cutting, one of the several no-pillar mining techniques, can actively change the structural shapes of the roadway roof and the roof of goaf by pressure relief by roof cutting. Furthermore, it retains the gob-side entry and nopillar mining by roof caving, and bulking of caved materials in goaf occurs [8]. The technique overcomes various problems (including waste of resources, difficulty in subsequent mining operations, and accumulation of gas in 
corners) induced by remaining coal pillars, improves the stress environment in roadways, and increases the safety and economic benefit of mines. The technique has been regarded as one of major directions guaranteeing the sustainable development of China's coal industry. To develop such nonpillar mining techniques, many researchers have investigated gob-side entry retention based on pressure relief by roof cutting. Compared with the traditional gob-side entry retention based on roadside packing, the gob-side entry-retaining technique based on roof cutting should be cut off the floor; the structure of surrounding rock and the stress distribution in the roof change after cutting; thus, it is necessary to investigate the roof structure and control techniques used when cutting a roadway. Based on the mechanism of pressure relief by roof cutting, He et al. [9] established several "surrounding rock structure-roadside support body" mechanical models, using surrounding rock control techniques such as constant-resistance large-deformation bolts and roadside props; Ma et al. [10] established mechanical models of the coal support area, dynamic pressure zones, and roadway table areas in gob-side entry retention formed by roof cutting, and the support system was constructed using NPR cables, pier-type unit supports, and I-beams. Gao et al. [11] theoretically studied changes in roof structures during the entire entry-retaining process, and the mechanical models of the roof during the entire entry-retaining process were established; the constant-resistance and large-deformation anchor cables, gangue prevention structures, and pier-beam unit supports were designed as entry-in support bodies. Fan et al. [12, 13] constructed a mechanical model of "surrounding rocksupporting body" for bolt-grouting controlled roof cutting for gob-side entry retaining; a grouting cable, a single prop, and a steel beam were used for roadway retention. Han et al. [14] established a lateral cantilever fractured structural mechanical model of gob-side entry retaining and found that the use of an unduly short cantilever would result in insufficient pressure relief and an unduly long cantilever would generate greater stresses in the roof, resulting in intense deformation. Guo et al. [15] constructed a mechanical model of the surrounding rock in a gob-side entry under conditions of roof cutting and without roof cutting: the surrounding rock control mechanism using blasting fracturing in the roof was analysed. Based on the principle of gob-side entry retention by roof cutting, Sun and Zhang et al. $[16,17]$ established a simplified mechanical model of the roof structure formed in the gob-side entry: the roadway was reinforced by large-deformation anchor cables, a lattice beam and a single prop, I-beam, and steel mesh.

In addition, scholars have conducted research into surrounding rock structures and roof control during gob-side entry retention based on roadside packing. Ning et al. [18] established a mechanical model of the support structure for gob-side entry retention using cement-based filling beside a roadway in inclined coal seams; a roadside backfill-truss support structure comprising three anchor bolts and a steel strip was adopted. Based on the gob-side entry-retention method involving the use of backfill material for wall construction, Du et al. [19] established a gob-side entry-retaining mechanical model and calculated the side support resistance; the gob-side entryretaining approach by backfilling was proposed. Yan et al. [20] proposed a roof-cutting mechanical model of gob-side entry retention with a roadside backfill body; the roof-cutting resistance and the width of the roadside backfill body were calculated. Luan et al. [21] analysed the surrounding rock structure formed in gob-side entry retention by building a concrete wall beside the roadway; bolt, cable, steel pipe, and angle irons were used to reinforce the surrounding rock. Wu et al. [22] presented a dynamic-equilibrium mechanical model of the main roof structure; the mechanisms of formation of different types of short cantilever rock beam structures were clarified. This review of the literature elucidates the significant contributions made to the understanding of surrounding rock structure and control techniques of gob-side entry retention: however, previous research into the roof structure was mainly aimed at near-horizontal coal seams; there are few studies on the roof structure of the retained roadway formed by roof cutting in inclined coal seams. The research into control techniques applicable to retained roadways was mainly based on engineering test data; there remains a lack of theoretical research on supporting mechanisms and techniques suited to retained roadways formed by roof cutting in inclined coal seams.

In view of this, the aims of this study were fourfold: (1) a mechanical model for surrounding rock structures in different subzones of a retained roadway in inclined coal seams was established, and a method of calculation of the support resistance in the roadway was determined. (2) The deformation characteristics of roadway roof in the process of retaining the roadway under the condition of roof cutting were studied. (3) The yielding supporting systems in different subzones and their constitutive models were constructed to ascertain the working principles and efficacy of the supporting systems. (4) The effect of the support system was verified by in situ testing. The results enrich the understanding on the mechanism of retained roadway formed by roof cutting and provide a reference and guidance for the technology's further promotion and application in inclined coal seams.

\section{Engineering Background}

The test was conducted based on the 110,301 working face of Taiping Coal Mine located in Xuanwei, Yunnan Province, China. The working face is at a burial depth of 50 to $150 \mathrm{~m}$, with a strike length of $600 \mathrm{~m}$ and a dip length of $125 \mathrm{~m}$ (it lies adjacent to the 110,303 working face). The working face is mined by using fully mechanised coal mining along the strike, with the retreating longwall moving by 4 to $5 \mathrm{~m} / \mathrm{d}$. The coal seam in the working face has a thickness of 1.2 to $1.8 \mathrm{~m}$, with an average thickness of $1.5 \mathrm{~m}$; the dip angle of the coal seam is between $25^{\circ}$ and $32^{\circ}$, with an average dip of $28^{\circ}$. The roof is siltstone with a thickness of $13.0 \mathrm{~m}$ while the floor of the coal seam in the working face is a silty mudstone of $18.7 \mathrm{~m}$ thickness. The basic conditions of the working face are shown in Figure 1.

\section{Materials and Methods}

3.1. Research Framework. Figure 2 depicts the framework of this study. Firstly, combined with the geological features and the 


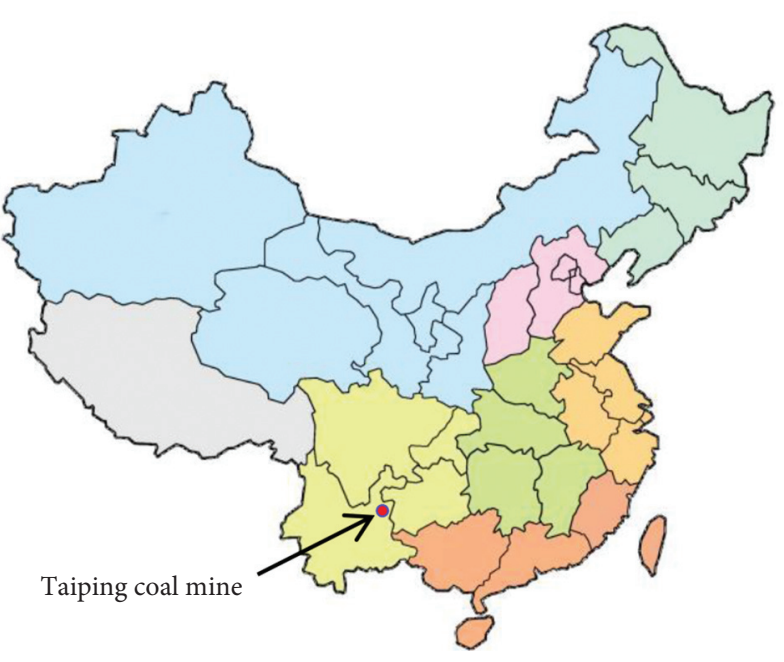

(a)

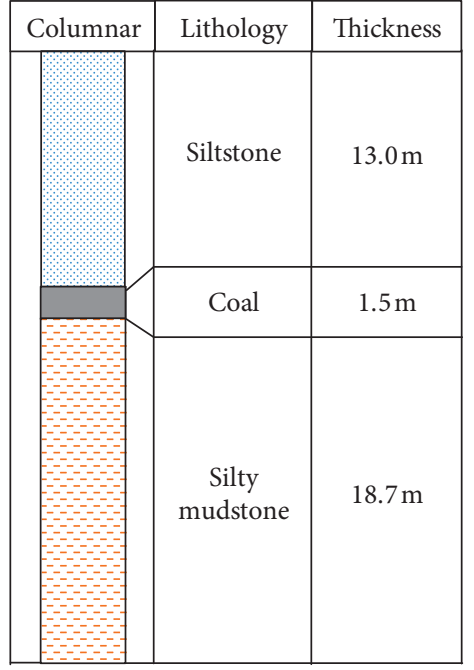

(b)

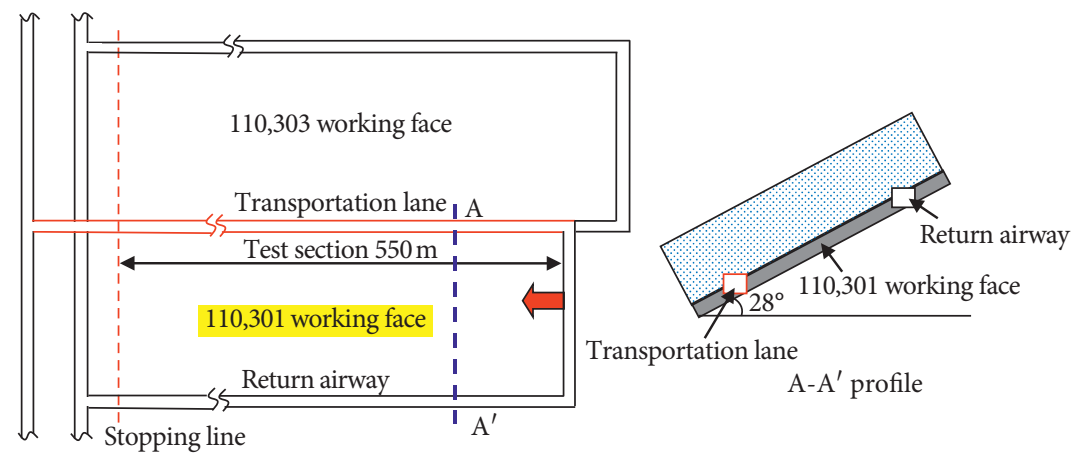

(c)

FIGURE 1: Engineering conditions: (a) geological situation; (b) geological column of working face; (c) working face layout.

principle of roadway retention as a result of roof cutting, the mechanical characteristics of the rock surrounding the retained roadway in different subzones were analysed; the deformation characteristics of the retained roadway roof were calculated by numerical simulation; and the mechanical characteristics of the support materials were also studied.

Secondly, combined with the mechanical characteristics of the retained roadway, the deformation characteristics of the retained roadway roof, and the mechanical characteristics of support materials, the supporting systems for roadways in different subzones and the constitutive model thereof were established, and the working principles and efficacy of the supporting system were analysed.

Thirdly, a full-scale engineering test was performed, and the support effect was assessed.

\subsection{The Mechanical Analysis of Surrounding Rocks of the Retained Roadway}

3.2.1. The Principle of Gob-Side Entry Retention through Pressure Relief by Roof Cutting. At the core of the gob-side entry-retention technique through pressure relief by roof cutting is the directional presplitting of the roof of the retained roadway along the direction of advance direction of the working face through bilaterally cumulative explosion. This can cut off the mechanical connection between the roof of the retained roadway and the goaf; additionally, the roadway roof is strengthened with negative Poisson's ratio (NPR) cables to enable the controllable deformation of the mined working face during entry retention. As the working face is advanced, the roof of the goaf is caved timeously along the cutting face and then bulked to support the overlying strata; finally, the roadway roof gradually stabilises, as shown in Figure 3 [23].

3.2.2. The Mechanical Analysis of Surrounding Rocks in Different Subzones. According to the principle of gob-side entry retention through pressure relief by roof cutting, gangues in goaf experience dynamic evolution such as caving, compaction, and stabilisation with the mining of the working face after presplitting cutting of the roof ahead of the working face. In this case, the corresponding surrounding rock structures in the roadway are also changed, leading to the difference of stress conditions. According to different stress conditions on surrounding rocks, the gobside roadway retained by roof cutting can be partitioned into an advanced zone, a dynamic pressure zone, and a stable zone (Figure 4). 


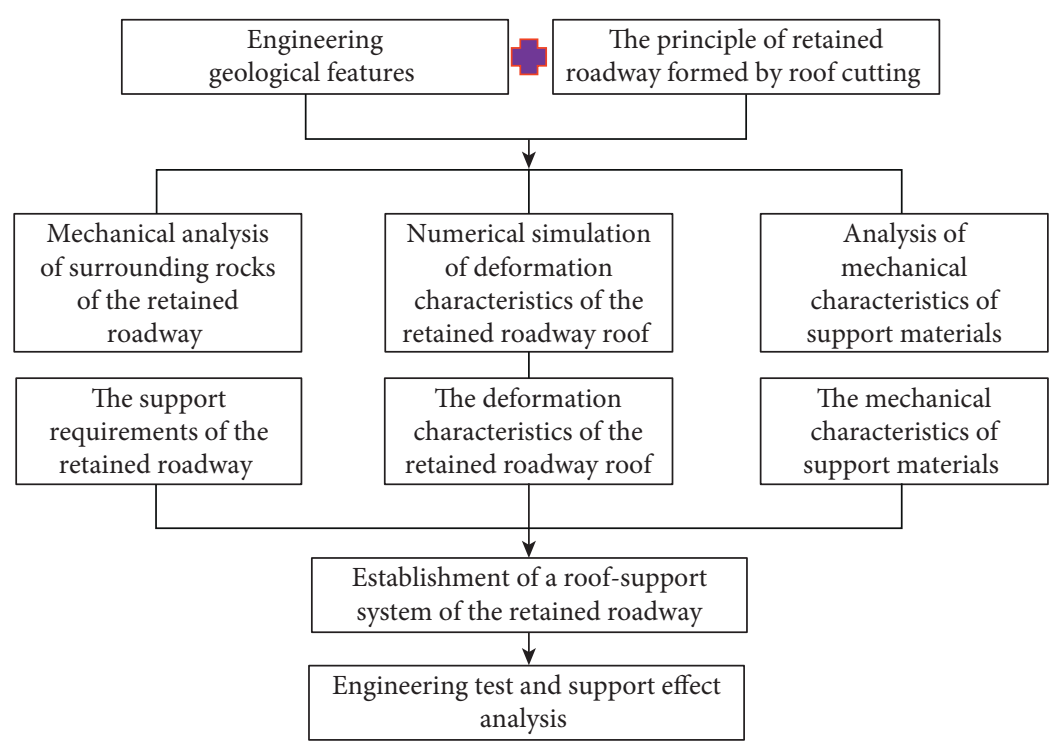

FIGURE 2: The framework of the present study.

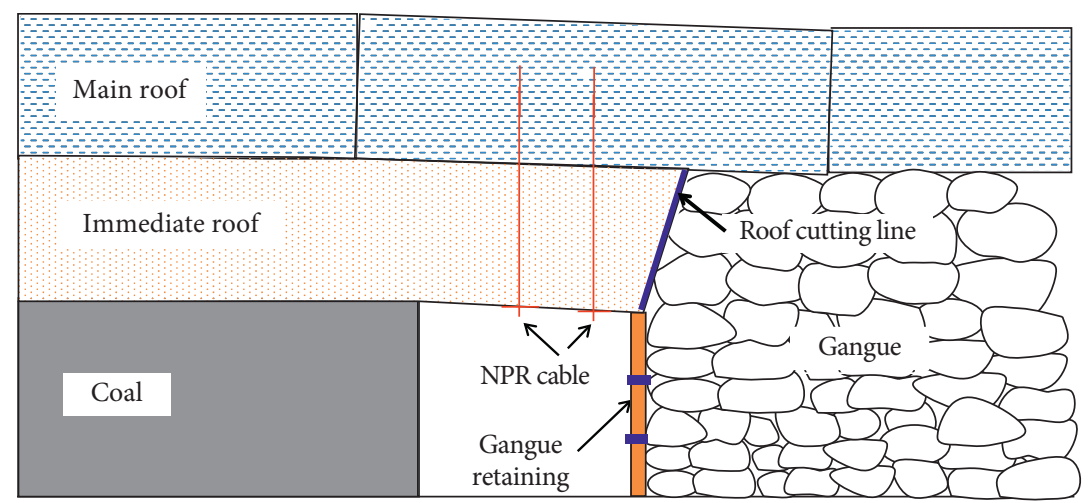

FIGURE 3: The principle of gob-side entry retaining through pressure relief by roof cutting.

The advanced zone of the retained roadway is located within a certain range ahead of the working face. In this case, although a cutting face has been formed in the roadway roof under the effect of cumulative explosion, the cutting face delivers a certain included angle with the vertical direction and coal can still provide the support force for the roadway roof. Therefore, the two ends of the roadway roof in the zone are supported by coal and are insignificantly deformed. The surrounding rock structure is demonstrated in Figure 4(a); the dynamic pressure zone of the retained roadway is located within a certain range at back of the working face. In this context, one end of the roadway roof is supported by coal while the other end is suspended. The gangues in the goaf within the zone are in constant motion, and thus they are greatly influenced by dynamic pressure. The surrounding rock structure is shown in Figure 4(b); the stable zone of the retained roadway is situated at back of the dynamic pressure zone, where the caved gangues in the goaf are compacted and the roadway roof does not subside any further. Furthermore, a stable structure with one end supported by coal and the other supported by caved gangues is formed. The surrounding rock structure is shown in Figure 4(c).
The simplified mechanical models for surrounding rocks in different subzones were established based on the characteristics of the surrounding rock structures. The deformation of the roof and the demand for support resistance in the corresponding subzones were calculated.

3.3. Numerical Simulation of Deformation Characteristics of the Roof during Entry Retention. Numerical simulation and laboratory test are popular methods used to study rock mechanics and engineering problems [24-26]. Continuum modelling approaches based on numerical simulation are appropriate with regard to large-scale engineering problems [27]; therefore, the continuous-medium software FLAC3D was selected to simulate the deformation characteristics of a roadway roof in the process of roadway retention.

According to geological conditions in the Taiping Coal Mine, the conveyor gateways of the 110,301 working face therein were simulated by using FLAC3D. The model measures $200 \times 100 \times 160 \mathrm{~m}$ (length $\times$ width $\times$ height $).$ The simulated working face has a dip length of $110 \mathrm{~m}$ and a strike length of $100 \mathrm{~m}$. Two conveyor gateways have a height of $2.55 \mathrm{~m}$, with the 


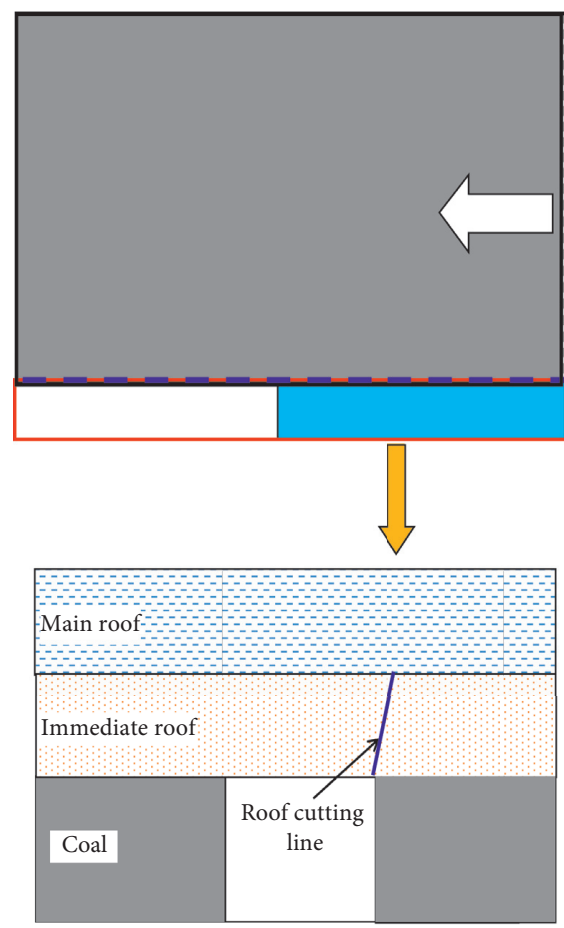

(a)

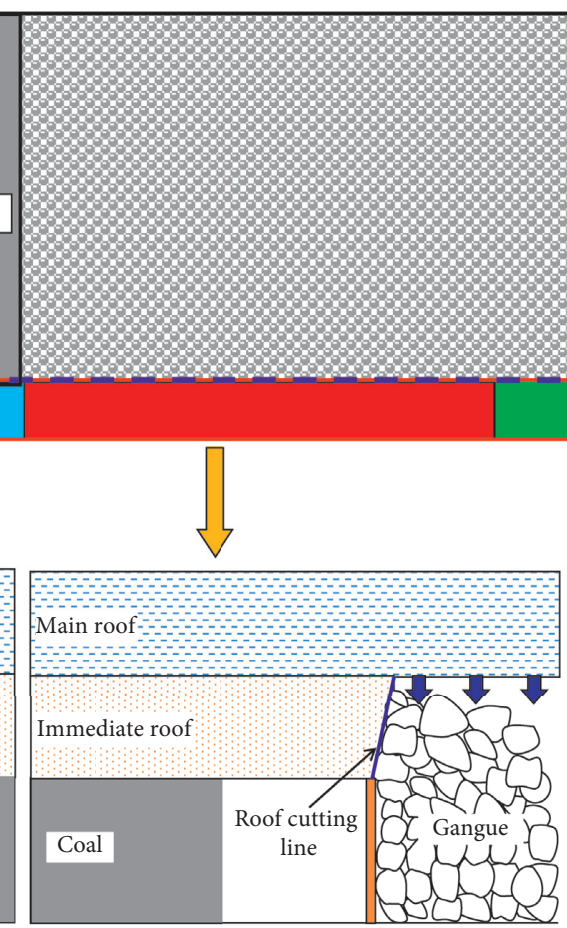

(b)
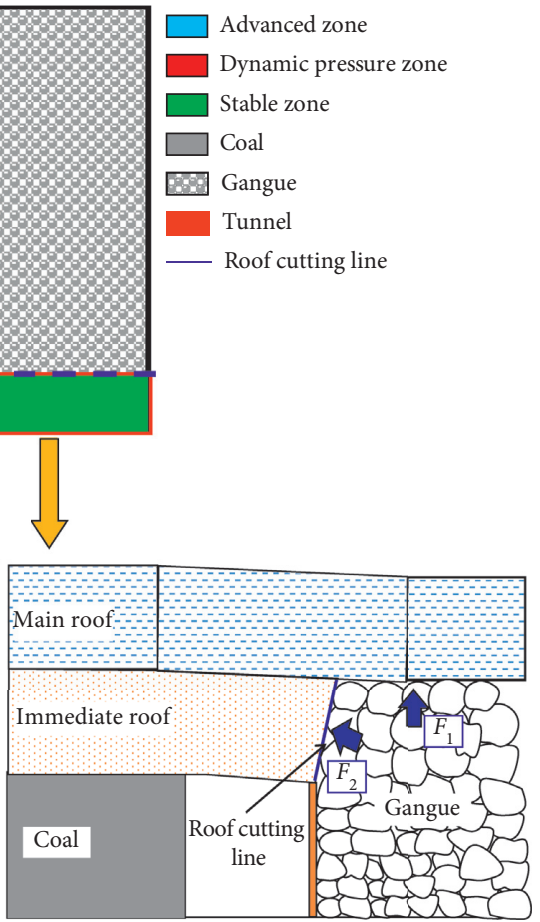

(c)

FIGURE 4: Zoning of the roadway retained through pressure relief by roof cutting and evolution process of surrounding rock structures: (a) advanced zone; (b) dynamic pressure zone; (c) stable zone. (In the figure, $F_{1}$ refers to the support force ( $\mathrm{kN}$ ) of the caved gangues in the goaf on the main roof, and $F_{2}$ denotes the pressure $(\mathrm{kN})$ on the immediate roof by caved gangues in the goaf.)

widths of the roof and floor being 3.6 and $4.4 \mathrm{~m}$, respectively. Two conditions (with and without roof cutting) were simulated, as shown in Figure 5. The constitutive model used was a Mohr-Coulomb model, the roof cutting was simulated by applying the null unit, and the goaf near the position of roof cutting was backfilled based on the strain-hardening model. The working face was excavated for $60 \mathrm{~m}$, and the model was loaded in 3000 steps. The physicomechanical parameters of various strata are listed in Table 1.

To compare the deformation characteristics of the retained roadway roof under the two conditions (with and without roof cutting), displacement-monitoring points were distributed in the middle part of the roadway roof at intervals of $10 \mathrm{~m}$ within the first $60 \mathrm{~m}$ behind the working face. On this basis, data pertaining to the change in vertical displacement of the roadway roof throughout the loading process under the two conditions were provided. The vertical displacement of the roof of the retained roadway was extracted from the model after completion of the calculations at positions shown in Figure 6.

\subsection{Supporting Material and Its Mechanical Characteristics.} Cable, bolt, single props, steel, and bolt-grouting reinforcement are commonly used methods to support the fractured surrounding rock in rock engineering $[28,29]$. The support material of the roadway formed by roof cutting involves three types: active support material such as negative Poisson's ratio (NPR) anchor cable, temporary support material in roadways such as single props, and support material with the gangue-retaining structure.

3.4.1. Active Support of the NPR Cables. The NPR cables are anchor cables which can be axially extended with increasing rock deformation to slowly absorb the produced energy during surrounding rock deformation [30]. The NPR cables have the properties of high constant resistance force, large elongation, and strong energy absorption [31]. Since the development of the NPR cable, it has been successfully applied to the stability control of many coal mines. The results are remarkable.

In terms of the core technology, the constant-resistance device is added to an ordinary anchor cable; consequently, the NPR cables maintain a constant resistance (preset artificially) and are deformed through relative slip in the interaction with surrounding rocks. The NPR cables are mainly subjected to elastic deformation when the load on the NPR cables is lower than the constant resistance; after the load reaches a constant resistance, the NPR cables start to slide and yield on the premise of keeping the resistance unchanged until the cables are stable again. The constitutive model of the NPR cables can be represented by using a SaintVenant body (S body), as shown in Figure 7 [10].

The NPR cables are deformed under the effect of the tension $\sigma$, whose total strain is equal to the sum of the strains in various elements. The stress-strain relationship of the NPR cables satisfies the following equation: 


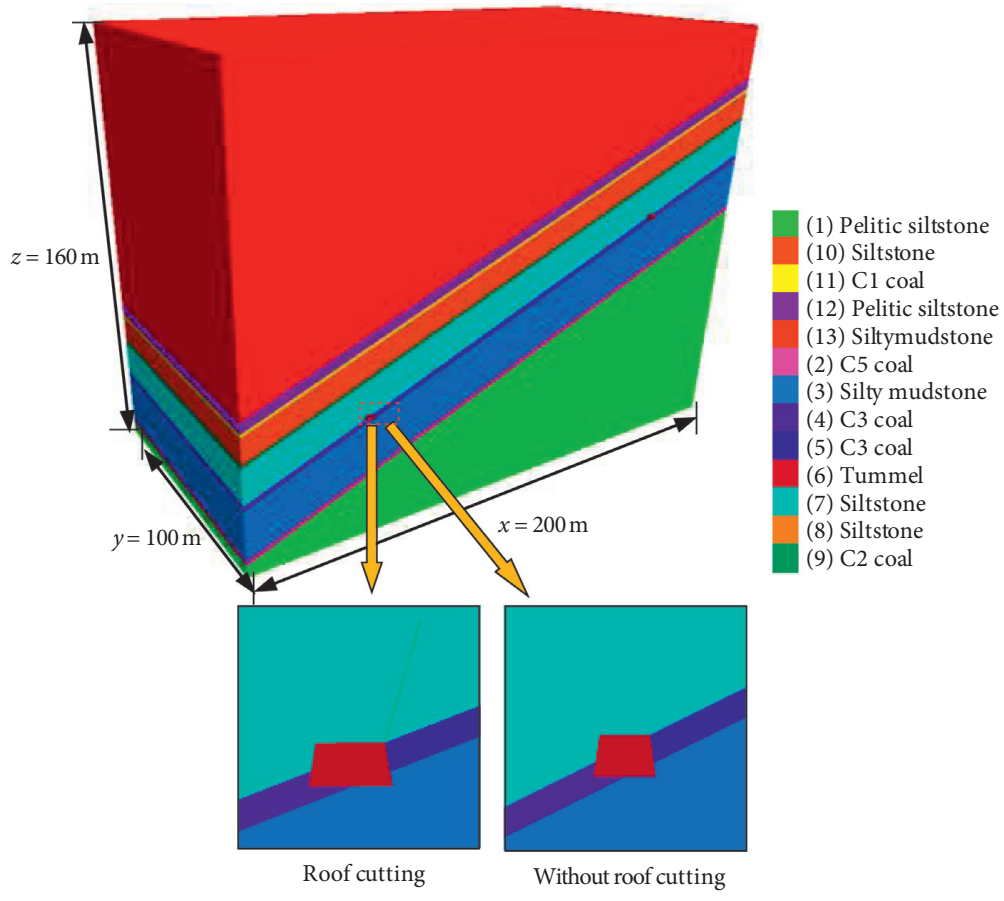

FIGURE 5: Numerical calculation model.

TABLE 1: Temperature and wildlife count in the three areas covered by the study.

\begin{tabular}{lcccccc}
\hline Lithology & $\begin{array}{c}\text { Density } \\
\left(\mathrm{kg} / \mathrm{m}^{3}\right)\end{array}$ & $\begin{array}{c}\text { Bulk modulus } \\
(\mathrm{GPa})\end{array}$ & $\begin{array}{c}\text { Tensile strength } \\
(\mathrm{MPa})\end{array}$ & $\begin{array}{c}\text { Shear modulus } \\
(\mathrm{GPa})\end{array}$ & $\begin{array}{c}\text { Friction angle }\left(^{\circ}\right) \\
\text { Cohesion } \\
(\mathrm{MPa})\end{array}$ \\
\hline Pelitic & & 6.81 & 2.90 & 4.45 & 25 & 0.90 \\
siltstone & 2460 & 8.50 & 4.30 & 6.65 & 30 & 2.30 \\
Siltstone & 2750 & 7.80 & 3.50 & 2.58 & 35 & 24 \\
Silty mudstone & 2600 & 2.80 & 0.40 & & & 0.68 \\
Coal & 1300 & & & &
\end{tabular}

$$
\sigma=\sigma_{1}=E_{2} \varepsilon_{2} .
$$

According to Figure 7 and (1), it can be found that the tension on the anchor cables increases with increasing $\varepsilon_{2}$ when the friction disk in the $S$ body does not slide; in the case that the friction disk in the $S$ body slides, $\sigma$ remains unchanged as $\varepsilon_{1}$ rises and $\varepsilon_{2}$ remains constant; therefore, the NPR cables show the following mechanical characteristics: the steel strands are subjected to the elastic deformation, and the support resistance provided by anchor cables grows with the increase of the deformation on condition that the tension is lower than the constant resistance; when the tension exceeds the constant resistance of the anchor cables, the anchor cables are able to adapt to surrounding rock deformation by slip of the constant-resistance device which takes over the role of the stretching of the steel strand; moreover, the resistance remains the same during the deformation of the anchor cables.

3.4.2. Temporary Support Using Single Props. The temporary support using single props mainly relies on the single hydraulic prop, which is composed of various parts including the cylinder block, movable column, and valves. In the case that the load applied to the prop exceeds the rated working resistance thereof, the high-pressure liquid in the internal cavity of the prop drives opens the safety valve, thus relieving the pressure. The constitutive model of the single hydraulic prop can be formed by connecting the $S$ body with a damping element ( $\mathrm{N}$ body) in parallel, as shown in Figure 8.

The single hydraulic prop is deformed under the effect of the pressure $\sigma$, whose total stress equals the sum of stresses of various elements and the total strain is equivalent to the sum of strains of various elements connected in parallel. The stress-strain relationship of the single hydraulic prop satisfies the following equation:

$$
\sigma=\sigma_{4}+\eta \frac{\mathrm{d} \varepsilon_{3}}{\mathrm{~d} t}=E_{5} \varepsilon_{5}+\eta \frac{\mathrm{d} \varepsilon_{3}}{\mathrm{~d} t} .
$$

It can be found from Figure 8 and (2) that when the pressure applied on the single props exceeds the rated working resistance, the support force provided by the single props is closely related to the rate of deformation. When the rate of deformation is large and the liquid fails to escape timeously through the safety valve, the total support force increases. Therefore, the single props exhibit the following mechanical characteristics: before reaching the rated working resistance, the support resistance provided by 


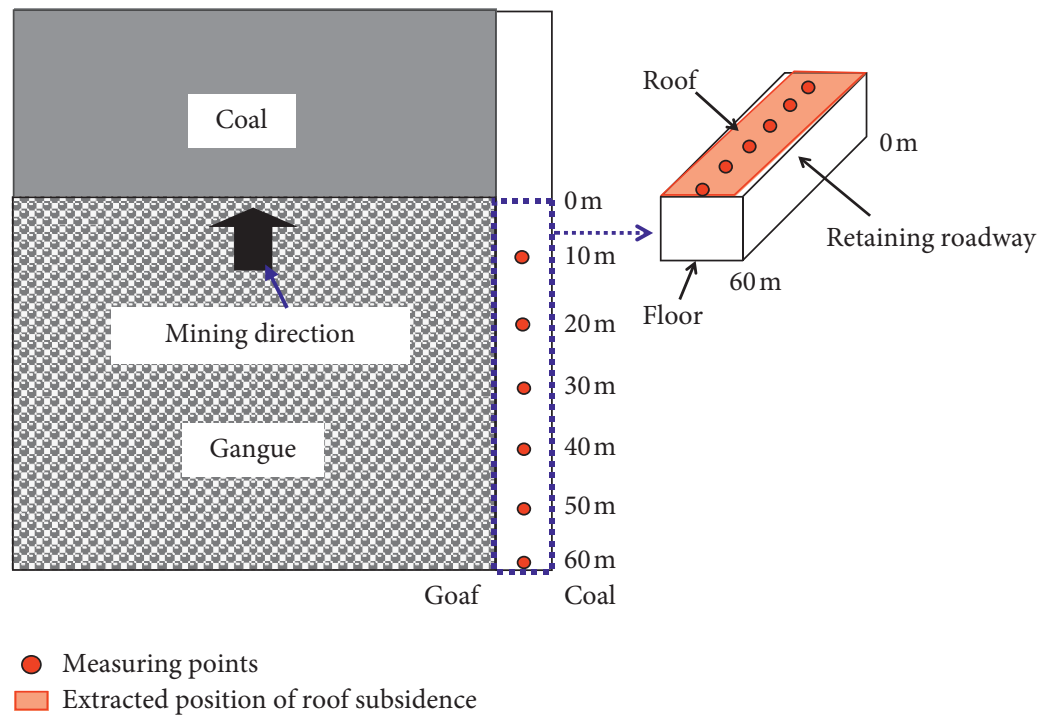

Figure 6: The distribution of monitoring points used to record roof displacement and the extraction position for the final subsidence of the roof.
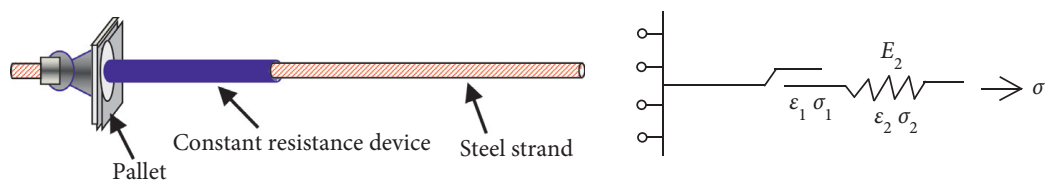

FIGURE 7: The NPR cable and its constitutive model. (in the figure, $\varepsilon_{1}$ and $\varepsilon_{2}$ separately refer to the yielding deformation of the constantresistance device and the elastic deformation of the steel strand; $\sigma_{1}$ and $\sigma_{2}$ represent the tensions applied to the constant-resistance device and steel strand of NPR cables, respectively; and $E_{2}$ and $\sigma$ denote the elastic modulus of the steel strand and the total tension applied to the NPR cables, with $\sigma=\sigma_{1}=\sigma_{2}$.)

single props rises with the growth of the external load; after reaching the rated working resistance, single props realise yielding by leakage of liquid through the safety valve. The support resistance remains unchanged if the liquid can be timeously leaked through the safety valve; otherwise, the support resistance increases. This indicates that single props are also able to control the rate of roof subsidence to prevent the occurrence of impact failure.

3.4.3. The Sliding-Type Gangue-Retaining Support Formed by U-Shaped Steel Inserts. The sliding-type gangue-retaining support structure is composed of two ordinary U-shaped steel members. Fastened by the clamping device, the two U-shaped steel members can undergo relative slip, thus realising collaborative deformation with the roadway roof. The frictional resistance between the two U-shaped steel members can be adjusted by controlling the torque applied to the clamping nuts. When the roof pressure is lower than the frictional resistance between the U-shaped steel members, they are mainly subjected to the elastic deformation and do not slide; the U-shaped members slide and yield when the roof pressure exceeds the frictional resistance between them. The constitutive model of the U-shaped steels can be expressed by use of an $\mathrm{S}$ body, as shown in Figure 9.

The stress-strain relationship of the sliding-type U-shaped steel members satisfies (3)); that is, they allow the support resistance to be the same during deformation, thus realising yielding under constant resistance. This guarantees that the roadway roof rotates and subsides in a controllable manner.

$$
\sigma=\sigma_{6}=E_{7} \varepsilon_{7} .
$$

As shown in Figure 9 and (3), the stress $\sigma$ remains unchanged as $\varepsilon_{5}$ rises and $\varepsilon_{6}$ remains constant when the friction disk in the $S$ body slides. Thus, the sliding-type gangue-retaining structure formed by U-shaped steel inserts delivers the following mechanical characteristics: when the pressure is less than the static friction between U-shaped members, the members are subjected to elastic deformation, and the support resistance provided by the gangue-retaining structure increases with the elastic deformation of the U-shaped steel members; when the pressure exceeds the static friction between the U-shaped steel members, the gangue-retaining structure is able to realise yielding through the sliding occurring between the two members, thus keeping the resistance unchanged during yielding.

3.5. Engineering Test. According to the geological conditions of the working face and the deformation characteristics of the roadway roof, the asymmetric support form in the roadway is determined to strengthen the roof in the side near the cutting. The specific parameters are shown as follows (Figure 10): (1) 

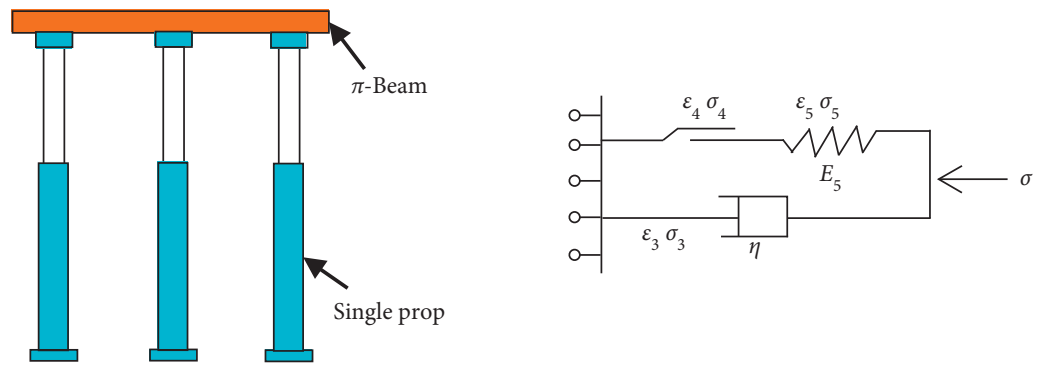

Figure 8: The single hydraulic prop and its constitutive model. (in the figure, $\varepsilon_{3}$ and $\varepsilon_{4}$ refer to the deformation induced by the liquid leakage from a single prop, with $\varepsilon_{3}=\varepsilon_{4} ; \varepsilon_{5}$ and $E_{5}$ separately denote the elastic deformation and the elastic modulus of single props; $\sigma_{4}$ and $\sigma_{5}$ refer to the support forces provided by single props, with $\sigma_{4}=\sigma_{5} ; \sigma_{3}$ denotes the increment of the support force caused by delay of liquid leakage of single props; and $\sigma$ denotes the total support force provided by single props, giving $\sigma=\sigma_{4}+\sigma_{3}=\sigma_{5}+\sigma_{3}$.)
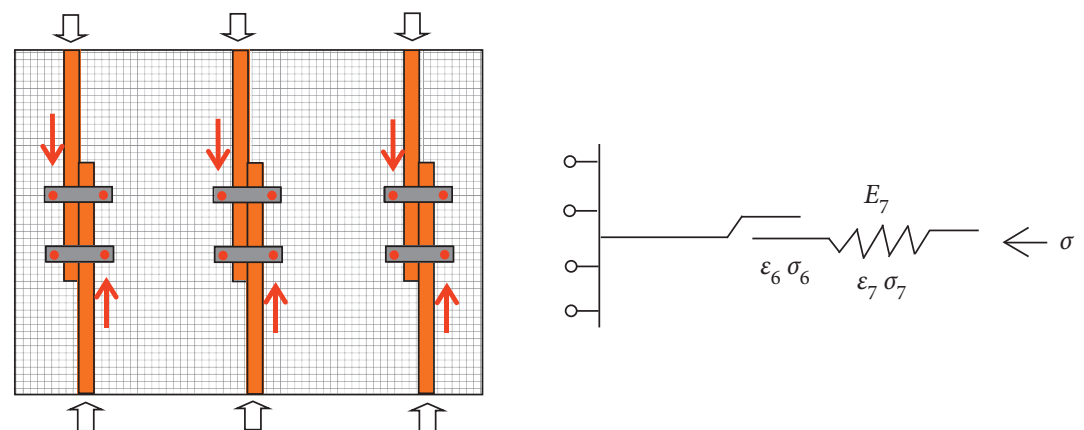

FIGURE 9: The sliding-type gangue-retaining structure formed by U-shaped steel inserts and its constitutive model. (in the figure, $\varepsilon_{6}$ and $\varepsilon_{7}$ refer to the sliding deformation and elastic deformation of the U-shaped steel inserts, respectively; $\sigma_{6}$ and $\sigma_{7}$ separately represent the friction between the two U-shaped steel members and the pressure applied thereon; and $E_{6}$ and $\sigma$ denote the elastic modulus of the U-shaped steel inserts and the total pressure applied to the gangue-retaining structure formed by U-shaped steel members, with $\sigma=\sigma_{6}=\sigma_{7}$.)

presplitting cutting to a depth of $7 \mathrm{~m}$ occurs $200 \mathrm{~mm}$ away from the upper corner of the roadway in the mining side; it shows the included angle of $15^{\circ}$ with the vertical direction and is inclined to the side of the mining working face (Figure 10(a)). (2) The spacing between blast holes is set to $500 \mathrm{~mm}$, with an explosive charging size of $\varphi 32 \times 330 \mathrm{~mm}$ and a charge structure of $2.5+2+2+1$ (Figure 10(b)). (3) Two columns of NPR cables are distributed at the roof, with the length and diameter of anchor cables of $9.3 \mathrm{~m}$ and $21.6 \mathrm{~mm}$, respectively. The first column of NPR cables is $300 \mathrm{~mm}$ away from the roof-cutting line, with a row spacing of $1 \mathrm{~m}$; these are connected with $\varphi 16 \mathrm{~mm}$ reinforced bar ladders along the strike of the roadway. The second column of NPR cables is $1300 \mathrm{~mm}$ from the first column, with a row spacing of $1800 \mathrm{~mm}$. (4) The temporary support is formed by using single props in combination with $\pi$-shaped beams with a length of $2.8 \mathrm{~m}$, with each beam having four columns. (5) The gangue-retaining structure is made of two $29 \mathrm{U}$-shaped steel inserts, and the spacing between adjacent supports is set to $500 \mathrm{~mm}$.

\section{Results}

\subsection{The Structural Model and Mechanical Analysis of Surrounding Rocks of the Retained Roadway Formed by Roof Cutting in Inclined Coal Seams}

4.1.1. Advanced Zone of the Retained Roadway. The roadway roof in the zone is synchronously supported by coal on two sides and the supporting structure in the roadway, whose simplified mechanical model is shown in Figure 11.

After presplitting cutting of the roof, the cutting face makes a certain included angle to the vertical. The coal still presents a certain supporting effect on the roadway roof. In this condition, the roadway roof can be regarded as a beam with one end clamped and the other end simply supported. Accordingly, the deflection of the roadway roof is given by

$$
\omega=-\frac{\left(q+q_{0}\right) \cos \alpha}{24 E I} x\left(a^{3}-2 a x^{2}+x^{3}\right),
$$

where $E$ and $I$ represent the elastic modulus $(\mathrm{MPa})$ and the sectional moment of inertia $\left(\mathrm{m}^{4}\right)$ of the beam, respectively.

It can be seen from (4) that the deflection of the roof is maximised at $x=a / 2$, as shown in the following equation:

$$
\omega_{\max }=-\frac{5 a^{4}\left(q+q_{0}\right) \cos \alpha}{384 E I} .
$$

In this case, the anchor bolts and anchor cables are taken as the main supporting structures of the roadway roof. Accordingly, it is feasible to calculate the support resistance $P_{i}$ in the roadway:

$$
P_{i}=a q_{0} \cos \alpha
$$

In the mining of the working face, the roadway roof not only bears the deadweight of the overlying strata but also suffers from the dual influence of the abutment pressure and 


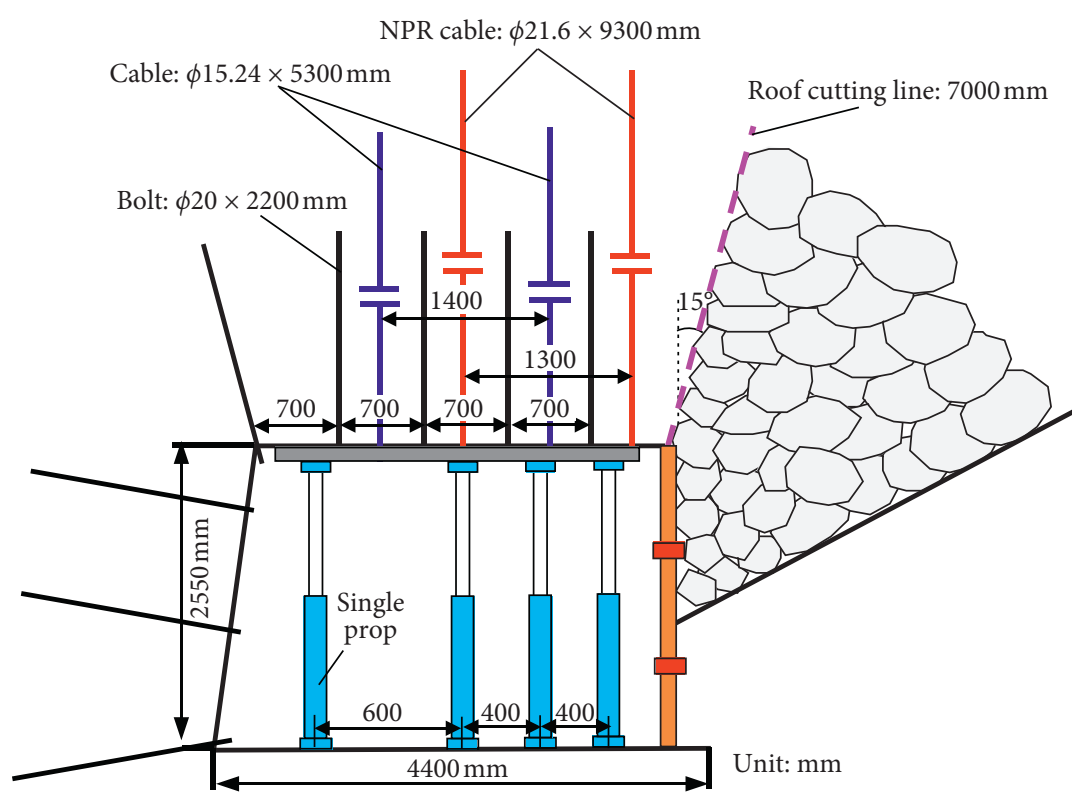

(a)

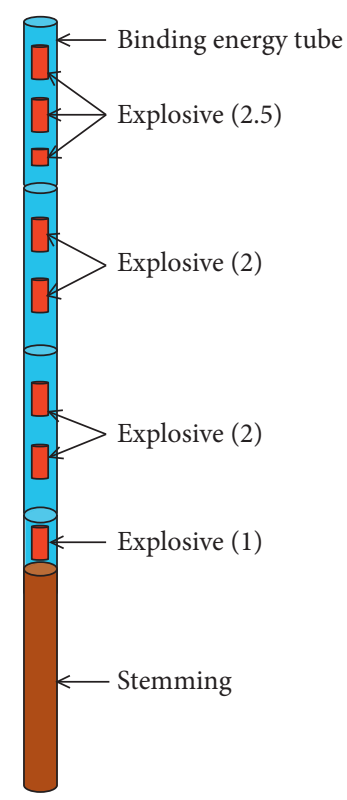

(b)

Figure 10: The designed parameters for gob-side entry formed by roof cutting: (a) design scheme; (b) charge structure.

the mining-induced dynamic pressure. Therefore, it is necessary to support the roadway roof within a certain range ahead of the working face to prevent damage under the influence of the dynamic pressure during the mining of the working face.

4.1.2. The Dynamic Pressure Area in the Retained Roadway. The gangues in the goaf within the area are in a state of nearcaving and they have not, as yet, effectively supported the roadway roof (Figure 12).

In this case, the roadway roof can be considered as a cantilever, whose deflection is given by

$$
\omega=-\frac{\left(q+q_{0}\right) \cos \alpha}{24 E I} x^{2}\left(x^{2}-4 a x+6 a^{2}\right) .
$$

When $x=a$, the defection of the roof reaches a maximum:

$$
\omega_{\max }=-\frac{a^{4}\left(q+q_{0}\right) \cos \alpha}{8 E I}
$$

The lateral fracture span $L$ of the strata in the main roof and the horizontal side thrusts on rock blocks $A\left(T_{A}\right)$ and $B$ $\left(T_{B}\right)$ are separately expressed as follows [32]:

$$
L=l\left(-\frac{l}{S}+\sqrt{\frac{l^{2}}{S^{2}}+\frac{3}{2}}\right)=x_{0}+a+e,
$$

where $L, S$, and $l$ refer to the lateral fracture span $(\mathrm{m})$ of the main roof, the length $(\mathrm{m})$ of the working face, and the step distance $(\mathrm{m})$ of periodic caving of the working face, respectively.

$$
T_{A}=\frac{q^{\prime} L \cos \alpha}{2\left(h-\Delta S_{A}\right)}
$$

where $q^{\prime}, h$, and $\Delta S_{A}$ separately denote the heavy load $(\mathrm{kN})$ of the main roof within the unit length, the thickness (m) of the main roof, and the subsidence $(\mathrm{m})$ of rock block $A$ at position $B^{\prime}$.

The width $x_{0}$ of the limit equilibrium zone within the coal sides and the support force $\sigma$ of the plastic zone on the coal are separately expressed as follows [33]:

$$
\begin{gathered}
x_{0}=\frac{h_{d} A}{2 \tan \phi} \ln \left(\frac{k \gamma H+\left(c_{0} / \tan \phi\right)}{\left(c_{0} / \tan \phi_{0}\right)+\left(p_{x} / A\right)}\right), \\
\sigma=\left(\frac{c_{0}}{\tan \phi}+\frac{p_{x}}{A}\right)^{2 x \tan \phi / h_{d} A}-\frac{c}{\tan \phi},
\end{gathered}
$$

where $c_{0}$ and $\varphi$ separately refer to the cohesion $(\mathrm{MPa})$ and internal friction angle $\left(^{\circ}\right)$ of the interfaces between the coal seams with the roof and floor strata; $h_{d}, A, k, \gamma, H$, and $p_{x}$ denote the thickness $(m)$ of the coal seams, the lateral pressure coefficient, the maximum stress concentration factor, the average bulk density $\left(\mathrm{kN} / \mathrm{m}^{3}\right)$ of strata, the mining depth $(\mathrm{m})$, and the support strength (MPa) of the coal sides, respectively.

In this context, it is feasible to perform stress analysis on rock blocks $A$ and $B$ by using the static equilibrium method to calculate the support resistance required to reach roadway stability.

As for rock block $B$, the static equilibrium equation can be attained according to $\sum F_{x}=0, \sum F_{y}=0$, and $\sum M_{B}=0$. 


$$
\begin{gathered}
T_{B}+q e \sin \alpha=T_{A}, \\
N_{A}=N_{B}+q e \cos \alpha, \\
M_{B}+T_{B}\left(h-\triangle S_{B}\right)-N_{B} e-\frac{q \cos \alpha}{2} e^{2}=0,
\end{gathered}
$$

According to (13) to (15), the shear forces on rock blocks $A\left(N_{A}\right)$ and $B\left(N_{B}\right)$ can be calculated:

$$
\begin{aligned}
& N_{B}=\frac{M_{B}+T_{B}\left(h-\Delta S_{B}\right)-q e^{2} \cos \alpha / 2}{e}, \\
& N_{A}=\frac{M_{B}+T_{B}\left(h-\Delta S_{B}\right)+q e^{2} \cos \alpha / 2}{e},
\end{aligned}
$$

As for rock block $A$, the following equation can be obtained according to $\sum M_{A}=0$ :

$$
M_{A}+M_{0}+P_{i}\left(x_{0}+b\right)+\int_{0}^{x_{0}} \sigma\left(x_{0}-x\right) \mathrm{d} x+T_{A}\left(h-\Delta S_{A}\right)-M_{B}-\frac{q\left(x_{0}+a\right)^{2} \cos \alpha}{2}-\frac{q_{0} \cos \alpha\left(x_{0}+a\right)^{2}}{2}-N_{A}\left(x_{0}+a\right)=0
$$

By simultaneously solving (10) to (18), the support resistance $P_{i}$ required to reach roadway stability can be calculated:

$$
P_{i}=\frac{1}{x_{0}+b} M_{B}-M_{A}-M_{0}-\int_{0}^{x_{0}} \sigma\left(x-x_{0}\right) \mathrm{d} x+\frac{\left(x_{0}+a\right)^{2}\left(q+q_{0}\right) \cos \alpha}{2}+\frac{\cos \alpha}{2}\left(q e\left(x_{0}+a\right)-q^{\prime} L\right)+\frac{1}{e}\left(x_{0}+a\right)\left(M_{B}+T_{B}\left(h-\Delta S_{B}\right)\right) .
$$

It can be seen from (8) that the roof of the retained roadway presents the maximum vertical displacement in the side of the roof cutting. Therefore, more attention must be paid to strengthening of the support on the roof in the side of the roof cutting of the roadway. As shown in Figure 11, the roadway roof is mainly supported by coal sides and the supporting structure in the roadway within the dynamic pressure area of the retained roadway. Thus, it is necessary to strengthen the support in the roadway based on the primary support. The resultant force on the support required for reach roadway stability can be calculated according to (19).

4.1.3. The Stable Zone within the Retained Roadway. The gangues in the goaf in the stable zone of the retained roadway have been completely caved and compacted; moreover, the rotation of the main roof and its overlying strata ceased. In this case, the broken gangues can support the rock beam; furthermore, the overburden strata movement stops, and the roadway roof tends to stabilise. In this condition, the simplified mechanical model of the roadway is shown in Figure 13.

As for rock block $B$, the following equation can be obtained according to (8):

$$
\begin{aligned}
N_{A}^{\prime} & =\frac{M_{B}^{\prime}+T_{B}^{\prime}\left(h-\Delta S_{B}^{\prime}\right)+q e^{2} \cos \alpha / 2}{e}-e F_{1}, \\
T_{A}^{\prime} & =\frac{q^{\prime} L \cos \alpha}{2\left(h-\Delta S_{A}^{\prime}\right)} .
\end{aligned}
$$

As for rock block $A$, the following equation can be attained based on $\sum M_{A}=0$ :

$$
M_{A}^{\prime}+M_{0}^{\prime}+P_{i}^{\prime}\left(x_{0}+b\right)+\int_{0}^{x_{0}} \sigma\left(x_{0}-x\right) \mathrm{d} x+T_{A}^{\prime}\left(h-\Delta S_{A}^{\prime}\right)-M_{B}^{\prime}-\frac{q\left(x_{0}+a\right)^{2} \cos \alpha}{2}-\frac{q_{0} \cos \alpha\left(x_{0}+a\right)^{2}}{2}-N_{A}^{\prime}\left(x_{0}+a\right)=0
$$


According to (20) to (22), the support resistance $P_{i}^{\prime}$ in the roadway within the stable zone of the retained roadway can be calculated:

$$
P_{i}^{\prime}=\frac{1}{x_{0}+b} M_{B}^{\prime}-M_{A}^{\prime}-M_{0}^{\prime}-\int_{0}^{x_{0}} \sigma\left(x-x_{0}\right) \mathrm{d} x+\frac{\left(x_{0}+a\right)^{2}\left(q+q_{0}\right) \cos \alpha}{2}+\frac{\cos \alpha}{2}\left(q e\left(x_{0}+a\right)-q^{\prime} L\right)+\frac{1}{e}\left(x_{0}+a\right)\left(M_{B}^{\prime}+T_{B}^{\prime} h-\Delta S_{B}^{\prime}-e^{2} F_{1}\right) .
$$

In (23), the support force imparted by gangues in the goaf on the roof can weaken the support resistance in the roadway. Therefore, it is essential to maximise the bearing capacity of the broken stone sides in the stable zone of the retained roadway. By comparing (23) with (19), it can be found that it is feasible to remove the temporary supports in the roadway progressively and in accordance with stressmonitoring results from the roadway: if $P_{i}>P_{i}^{\prime}$, all temporary supports in the roadway are removed.

It can be seen from (6), (19), and (23) that the demands for support resistance in the roadway within different subzones all gradually reduce with increasing dip angle. The maximum deflection of the roof in the dynamic pressure area of the retained roadway is found near the mining side. Therefore, strengthening of the roof near the mining side warrants greater attention, thus reducing the support cost on the premise of guaranteeing roof stability.

4.2. Analysis of Deformation Characteristics of the Roof during Entry Retention by RoofCutting. Figure 14 shows changes at different positions of the roof of the retained roadway under load (under both conditions). It can be seen from the figure that the roadway roof is always deformed in conditions without roof cutting. The average subsidence of the roadway roof reaches $1.52 \mathrm{~m}$ at the end of the loading stage; after pressure relief by roof cutting, the roadway roof gradually stabilises after 2000 loading steps. The average subsidence of the stabilised roadway roof is $0.55 \mathrm{~m}$, which decreases by $64 \%$ compared with the result before roof cutting.

The nephogram of the vertical displacement of the roof is drawn, as shown in Figure 15. According to the spatial characteristics of the roof subsidence, the positions with the maximum subsidence of the roadway roof under the two conditions are both on the side near the goaf (roof cutting), which conforms to the result deduced from (25). After pressure relief by roof cutting, the average roof subsidence in the side near roof cutting within the range of $60 \mathrm{~m}$ behind the working face is $0.55 \mathrm{~m}$; at the same position, the average subsidence of the roadway roof without roof cutting reaches $2.78 \mathrm{~m}$, which is five times as large as that in former case. In this condition, this means that failure and collapse have occurred in the roadway.

\subsection{Establishment of a Roof-Support System in Different Subzones}

4.3.1. The Advanced Zone of the Retained Roadway. The rock mechanical properties will gradually become weaker under the blasting and construction disturbances [34]. The roadway roof weakens slightly under the influence of the top cutting blasting and mining-induced dynamic pressure. The supporting system in the zone can be constructed by applying NPR cables and single props, as shown in Figure 16. According to analysis in Section 3.4, the constitutive model of the supporting system is formed by connecting the $S$ body and a Coulomb body in parallel (known as the S-N-S model), as shown in Figure 16.

Under these parallel conditions, the total stress on the supporting system is the sum of the stresses on various parallel elements, and the total strain is equivalent to the total of the strains in various parallel elements, shown as follows:

$$
\begin{aligned}
& \varepsilon=\varepsilon_{1}+\varepsilon_{2}=\varepsilon_{3}=\varepsilon_{4}+\varepsilon_{5}, \\
& \varepsilon=\varepsilon_{1}+\varepsilon_{2}=\varepsilon_{3}=\varepsilon_{4}+\varepsilon_{5} .
\end{aligned}
$$

The constitutive equation of the model is expressed as follows:

$$
\begin{aligned}
\sigma & =E_{2} \varepsilon_{2}+E_{5} \varepsilon_{5}+\eta \frac{\mathrm{d} \varepsilon_{3}}{\mathrm{~d} t}=E_{2} \varepsilon_{2}+E_{5} \varepsilon_{5}+\eta \frac{\mathrm{d} \varepsilon}{\mathrm{d} t}, \\
\lim _{\varepsilon \longrightarrow \varepsilon_{s_{1}}} \sigma & =E_{2}\left(\varepsilon_{s_{1}}-\varepsilon_{1}\right)+E_{5}\left(\varepsilon_{s_{2}}-\varepsilon_{4}\right)+\eta \frac{\mathrm{d} \varepsilon_{s_{1}}}{\mathrm{~d} t} .
\end{aligned}
$$

On condition that the roof bears only a low pressure, the supporting system is not subjected to yielding deformation ( $\varepsilon_{1}$ and $\varepsilon_{4}$ equal zero). The support resistance of the supporting system is mainly offered by the NPR cables and single props in the form of the elastic deformation, which is calculated as follows:

$$
\lim _{\varepsilon \longrightarrow \varepsilon_{s_{1}}} \sigma=\left(E_{2}+E_{5}\right) \varepsilon_{\mathcal{s}_{2}}+\eta \frac{\mathrm{d} \varepsilon_{s_{1}}}{\mathrm{~d} t} .
$$

When the roof pressure is high, the supporting system is subjected to yielding deformation ( $\varepsilon_{1}$ and $\varepsilon_{4}$ are nonzero). The support resistance of the supporting system is mainly provided by the constant resistance $\sigma_{1}$ of the NPR cables and the rated working resistance $\sigma_{4}$ of single props, which is calculated as follows:

$$
\lim _{\varepsilon \longrightarrow \varepsilon_{s_{1}}} \sigma=\sigma_{1}+\sigma_{4}+\eta \frac{\mathrm{d} \varepsilon_{s_{1}}}{\mathrm{~d} t}
$$

According to (27) and (28), it can be found that the support system for the advanced zone of the retained 


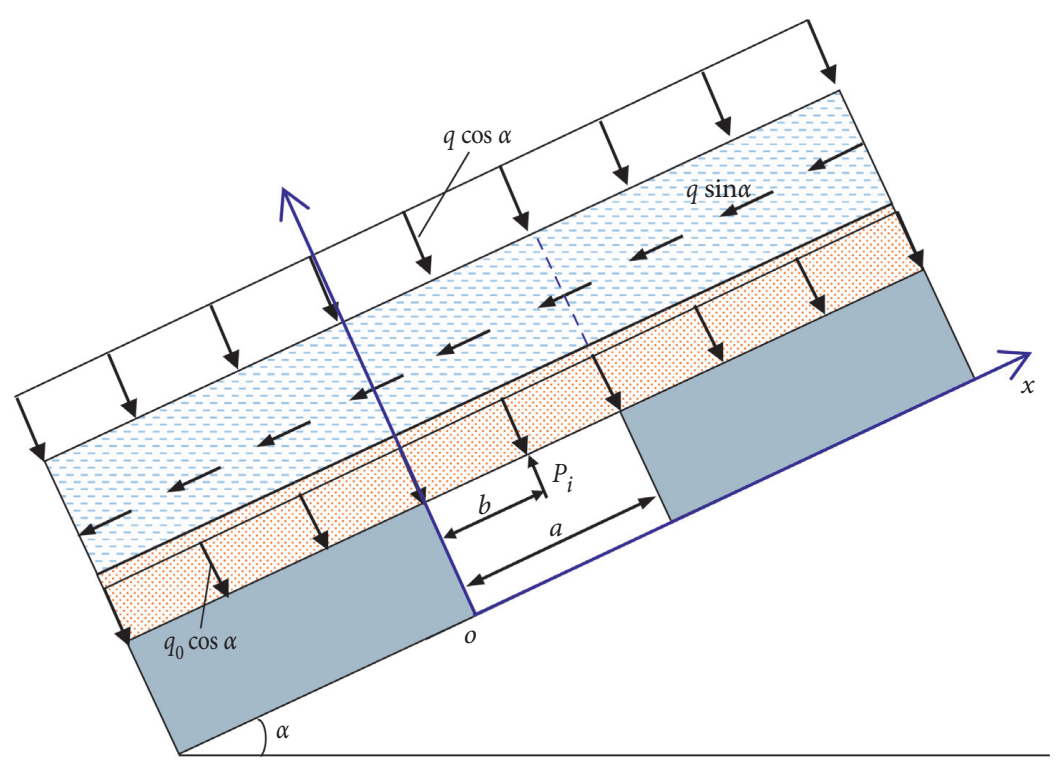

FIGURE 11: The simplified mechanical model for the advanced zone of the retained roadway. (in the figure, $q$ refers to the deadweight $(\mathrm{kN} / \mathrm{m})$ of the main roof and the average load from the overlying strata; $\alpha, q_{0}, P_{i}, a$, and $b$ denote the dip angle $\left(^{\circ}\right)$ of strata, the average load (kN/m) generated by the deadweight of the immediate roof, the average support resistance $(\mathrm{kN})$ in the roadway, the width $(\mathrm{m})$ of the retained gobside roadway, and the distance $(\mathrm{m})$ between the position where $P_{i}$ is applied and the coal sides, respectively.)

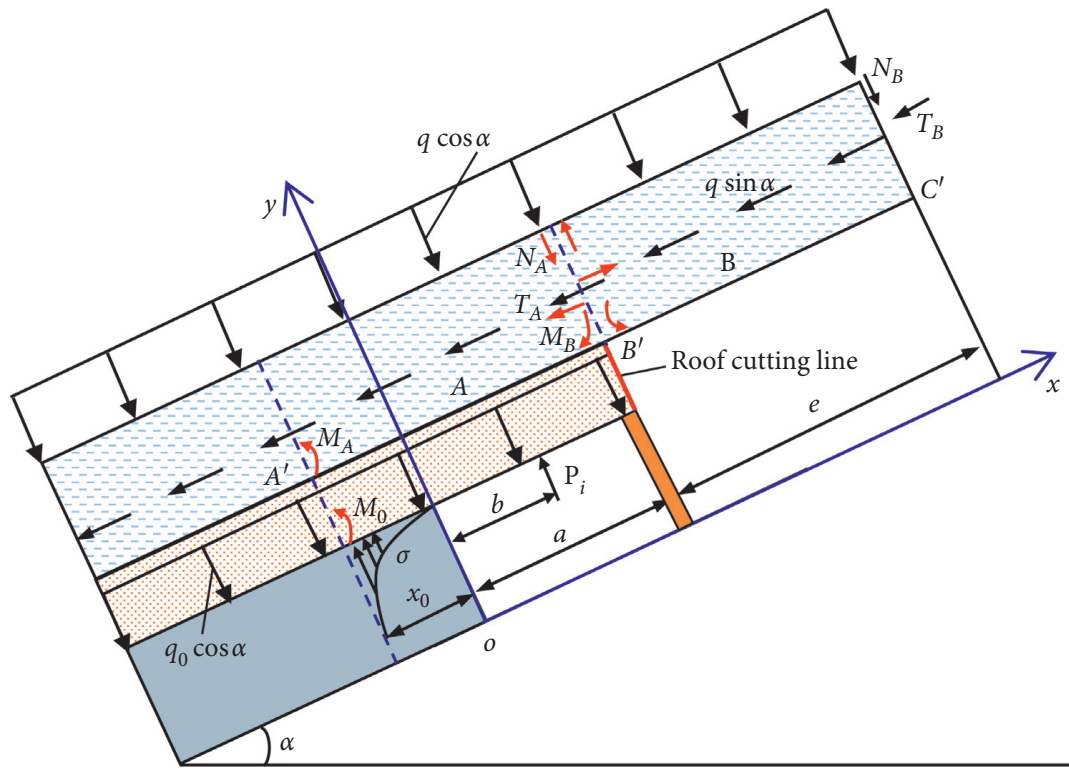

Figure 12: The simplified mechanical model of the dynamic pressure area in the retained roadway. (in the figure, $T_{B}$ and $T_{A}$ denote the side thrust $(\mathrm{kN})$ on rock block $B$ at position $C^{\prime}$ and that $(\mathrm{kN})$ on rock block $A$ at position $B^{\prime}$, respectively; $N_{B}$ and $N_{A}$ represent the shear forces $(\mathrm{kN})$ on rock blocks $B$ and $A ; \sigma$ and $x_{0}$ denote the support force $(\mathrm{kN})$ from the coal in the plastic zone on the roof and the width (m) of the limit equilibrium zone in the coal, respectively; $M_{A}$ and $M_{B}$ refer to the residual moments $(\mathrm{kN} \cdot \mathrm{m})$ on the rock beam at positions $A^{\prime}$ and $B^{\prime}$; and $M_{0}$ denotes the bending moment $(\mathrm{kN} \cdot \mathrm{m})$ caused by the action of the immediate roof on the main roof.)

roadway shows the following mechanical characteristics: the support resistance increases with increasing external load. After reaching the maximum support resistance of the support units, the system enables yielding deformation and maintains constant stiffness during deformation.
4.3.2. The Dynamic Pressure Area of the Retained Roadway. Under the disturbance of the caving of gangues in the goaf and overburden strata movement, the surrounding rock of roadway is prone to dynamic disaster, which influences the long-time stability of rock structures and rock engineering 


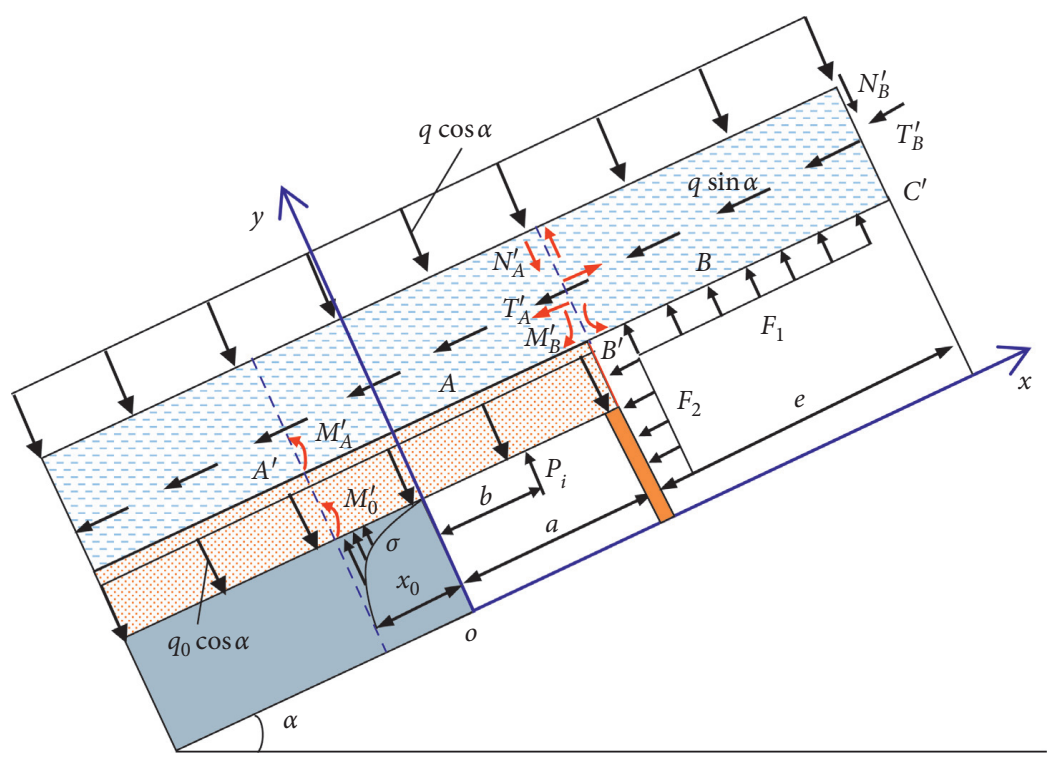

FIGURE 13: The simplified mechanical model of the stable zone in the retained roadway. (in the figure, $F_{1}$ refers to the support force (kN) of the caved gangues in the goaf on the main roof and $F_{2}$ denotes the pressure $(\mathrm{kN})$ on the immediate roof and the gangue-retaining structure by caved gangues in the goaf; $T_{B}^{\prime}$ and $T_{A}^{\prime}$ separately represent the side thrust $(\mathrm{kN})$ on rock block $B$ at position $C^{\prime}$ and that (kN) on rock block $A$ at position $B^{\prime} ; N_{B}^{\prime}$ and $N_{A}^{\prime}$ denote the shear forces $(\mathrm{kN})$ on rock blocks $B$ and $A$, respectively; $\sigma$ and $x_{0}$ separately refer to the support force $(\mathrm{kN})$ on the coal mass in the plastic zone on the roof and the width $(\mathrm{m})$ of the limit equilibrium zone in coal, respectively; $M_{A}^{\prime}$ and $M_{B}^{\prime}$ denote the residual bending moments $(\mathrm{kN} \cdot \mathrm{m})$ on the rock beam at positions $A^{\prime}$ and $B^{\prime}$; and $M_{0}^{\prime}$ refers to the bending moment (kN.m) caused by the action of the immediate roof on the main roof, respectively.)

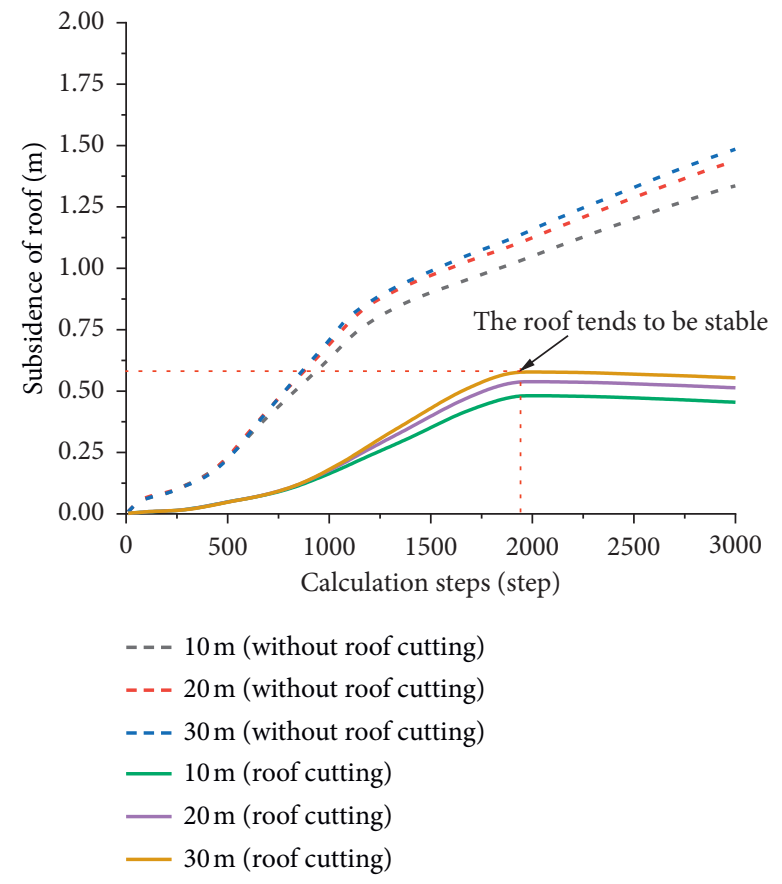

(a)

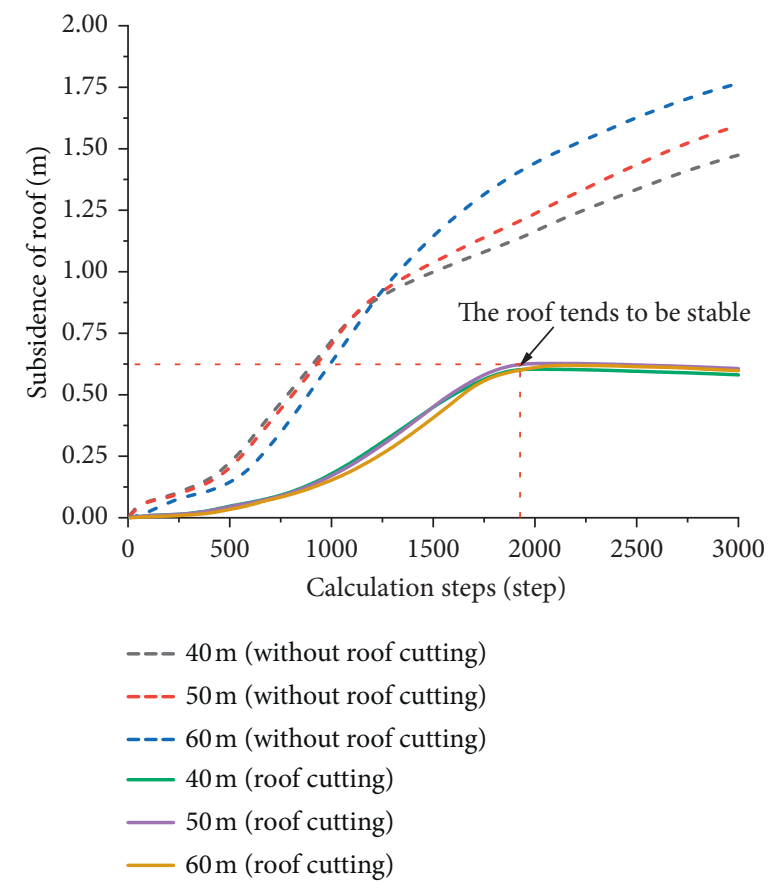

(b)

Figure 14: Roof subsidence of the roadway before and after roof cutting: (a) 10 to $30 \mathrm{~m}$ behind the working face; (b) 40 to $60 \mathrm{~m}$ behind the working face.

[35]. This requires the supporting system in the roadway to provide sufficient resistance to control the rate of roof subsidence, so that the rock beams can make contact with the gangues in a slow and controlled manner; therefore, it is necessary to establish the supporting system by utilising the NPR cables, the single props, and the sliding-type gangueretaining structure formed by $\mathrm{U}$-shaped steel members. In this case, the combined constitutive model of the three 


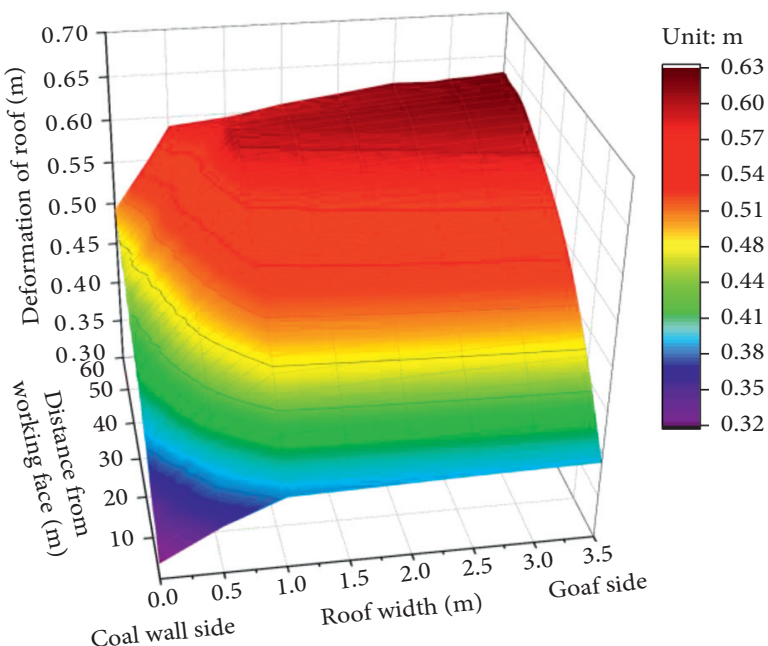

(a)

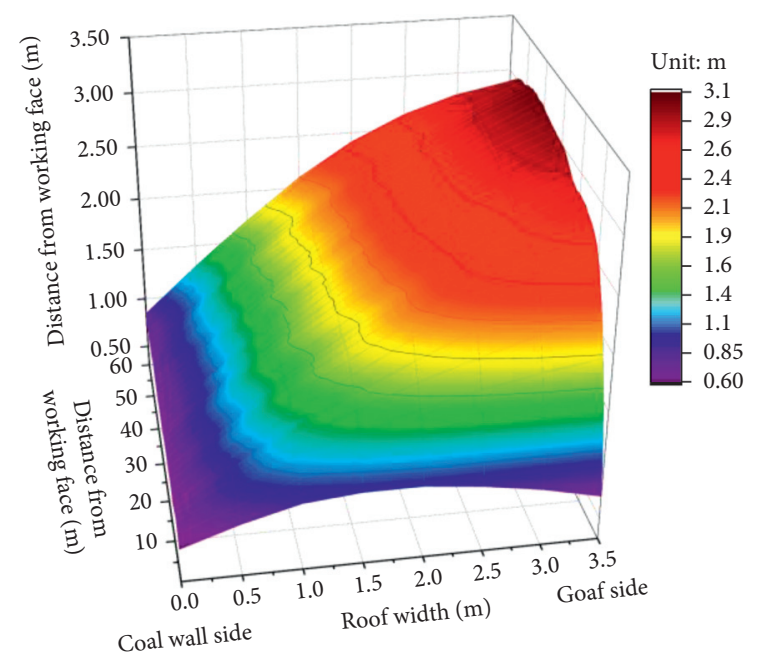

(b)

FIGURE 15: Nephogram of the vertical displacement of the roadway roof: (a) pressure relief by roof cutting; (b) conventional conditions.

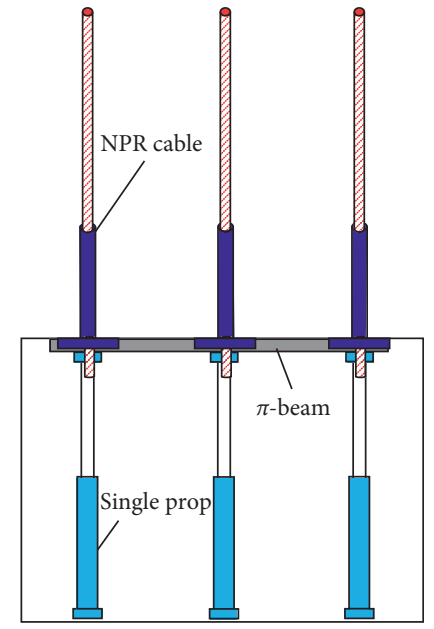

(a)

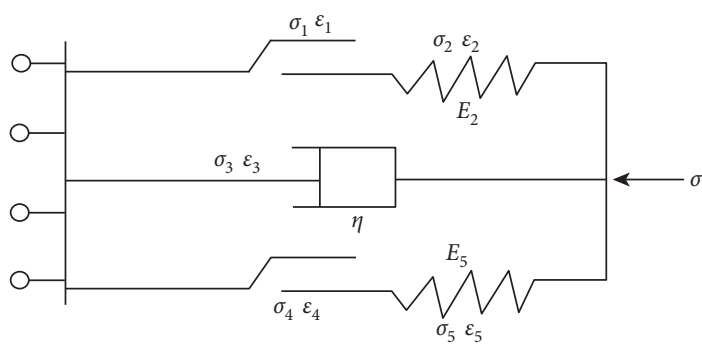

(b)

FIGURE 16: The supporting system of the advanced zone of the retained roadway and its constitutive model.

support units is formed by connecting three $\mathrm{S}$ bodies and a Coulomb body in parallel (known as the S-N-S-S model), as shown in Figure 17.

The stress on various units is equal to the sum of stresses on various parallel elements, and the total strain is equivalent to the strains in various parallel elements, as given by the following equations:

$$
\begin{aligned}
& \varepsilon=\varepsilon_{1}+\varepsilon_{2}=\varepsilon_{3}=\varepsilon_{4}+\varepsilon_{5}=\varepsilon_{6}+\varepsilon_{7}, \\
& \sigma=\sigma_{1}+\sigma_{3}+\sigma_{4}+\sigma_{6}=\sigma_{2}+\sigma_{3}+\sigma_{5}+\sigma_{7} .
\end{aligned}
$$

The constitutive equation for the model is expressed as follows:

$$
\sigma=E_{2} \varepsilon_{2}+E_{5} \varepsilon_{5}+\eta \frac{\mathrm{d} \varepsilon_{3}}{\mathrm{~d} t}+E_{7} \varepsilon_{7}=E_{2} \varepsilon_{2}+E_{5} \varepsilon_{5}+\eta \frac{\mathrm{d} \varepsilon}{\mathrm{d} t}+E_{7} \varepsilon_{7} .
$$

The support resistance is given by

$$
\lim _{\varepsilon \longrightarrow \varepsilon_{s_{2}}} \sigma=E_{2}\left(\varepsilon_{s_{2}}-\varepsilon_{1}\right)+E_{5}\left(\varepsilon_{s_{2}}-\varepsilon_{4}\right)+\eta \frac{\mathrm{d} \varepsilon_{s_{2}}}{\mathrm{~d} t}+E_{7}\left(\varepsilon_{s_{2}}-\varepsilon_{6}\right) .
$$

When the roof pressure is low, the supporting system is not subjected to yielding deformation $\left(\varepsilon_{1}, \varepsilon_{4}\right.$, and $\varepsilon_{6}$ are zero). The support resistance of the supporting system is mainly offered by the elastic deformation of the NPR cables, the single props, and the gangue-retaining structure formed by U-shaped steel members, as given by

$$
\lim _{\varepsilon \longrightarrow \varepsilon_{s_{2}}} \sigma=\left(E_{2}+E_{5}+E_{7}\right) \varepsilon_{s_{2}}+\eta \frac{\mathrm{d} \varepsilon_{s_{2}}}{\mathrm{~d} t} .
$$

On condition that the roof bears high pressure, the supporting system undergoes yielding deformation $\left(\varepsilon_{1}, \varepsilon_{4}\right.$, and $\varepsilon_{6}$ are nonzero). The support resistance of the supporting system is mainly provided by the constant resistance $\sigma_{1}$ of 


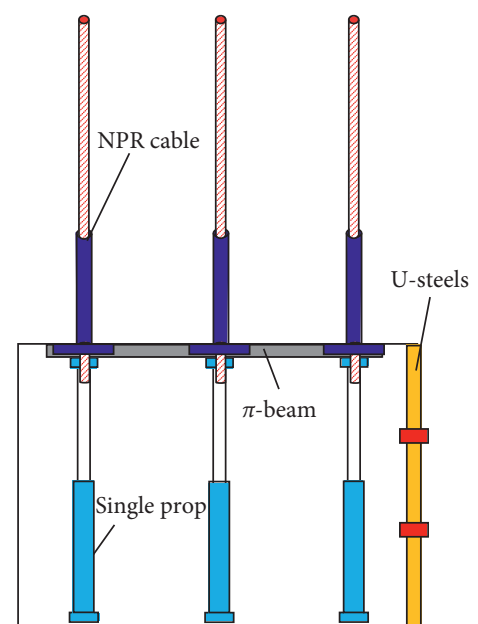

(a)

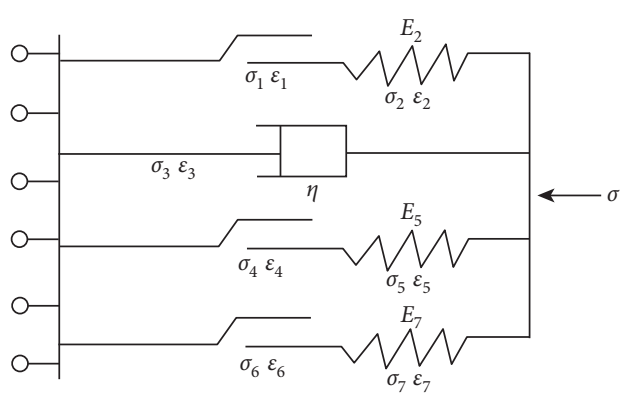

(b)

FIgURE 17: The supporting system for the dynamic pressure area of the retained roadway and its constitutive model.

the NPR cables, the rated working resistance $\sigma_{4}$ of single props, and the maximum static friction $\sigma_{5}$ between $\mathrm{U}$-shaped steel members in the gangue-retaining structure, as given by

$$
\lim _{\varepsilon \longrightarrow \varepsilon_{s_{2}}} \sigma=\sigma_{1}+\sigma_{4}+\sigma_{5}+\eta \frac{\mathrm{d} \varepsilon_{s_{2}}}{\mathrm{~d} t} .
$$

According to (32) and (33), the mechanical characteristics of the supporting system for the dynamic pressure area of the retained roadway are shown as follows: different support units can be collaboratively deformed. When various support units do not reach their maximum support resistance, the support resistance provided by the supporting system gradually increases with increasing roof deformation. After the support resistances of various support units all reach the maximum, the maximum resistance provided by the supporting system is related to the rate and amount of compression of the single props. Therefore, $\mathrm{d} \varepsilon / \mathrm{d} t$ in (33) can be regarded as a fixed value; afterwards, $\sigma$ also becomes a fixed value with the change of $\varepsilon$. This implies that the supporting system can realise yielding under constant resistance after reaching the maximum support resistance, thus realising collaborative deformation between the roof and the supporting structure. Furthermore, the roof pressure is transferred to the gangues in the goaf. If the support strength is not sufficient, $\mathrm{d} \varepsilon / \mathrm{d} t$ becomes extremely large, bursting or bending the single props, thus risking a collapse.

4.3.3. The Stable Zone of the Retained Roadway. The mininginduced dynamic pressure disappears, and the gangues in the goaf can support the roadway roof and its overlying strata. Thus, the roadway roof tends to stabilise. On this condition, the rock beam of the main roof is supported by coal and gangues to form a stable structure. The immediate roof is suspended below the main roof with the NPR cables. Therefore, it is feasible to withdraw the single props and retain the NPR cables and the sliding-type gangue-retaining structure to support the roof and retain gangues. In this case, the combined constitutive model for the two support units is formed by using two $S$ bodies connected in parallel (known as the S-S model), as shown in Figure 18.

On this condition, the relationships between the total stress and strain of the supporting system with stresses and strains of various parallel elements satisfy the following equations:

$$
\begin{aligned}
& \sigma=\sigma_{1}+\sigma_{6}=\sigma_{2}+\sigma_{7}, \\
& \varepsilon=\varepsilon_{1}+\varepsilon_{2}=\varepsilon_{6}+\varepsilon_{7} .
\end{aligned}
$$

The constitutive equation of the model is shown as follows:

$$
\sigma=E_{2} \varepsilon_{2}+E_{7} \varepsilon_{7}
$$

The support resistance provided by the supporting system is calculated as follows:

$$
\lim _{\varepsilon \longrightarrow \varepsilon_{s_{3}}} \sigma=E_{2}\left(\varepsilon_{s_{3}}-\varepsilon_{1}\right)+E_{7}\left(\varepsilon_{s_{3}}-\varepsilon_{6}\right) .
$$

In this stage, the roadway roof tends to stabilise, so it can be thought that the total deformation $\varepsilon$ of the supporting system stabilises; thus, both $\varepsilon_{1}$ and $\varepsilon_{6}$ are zero in (36). The support force offered by the supporting system is calculated as follows:

$$
\lim _{\varepsilon \longrightarrow \varepsilon_{s_{3}}} \sigma=\left(E_{2}+E_{7}\right) \varepsilon_{s_{3}} .
$$

Therefore, the supporting system for the stable zone of the retained roadway can still provide the constant support resistance for the roadway roof. On this condition, the roadway roof remains stable under the combined support of the gangues in the goaf, the NPR cables, and the sliding-type gangue-retaining structure formed by the U-shaped steel members. Without being disturbed, the pressure on the supporting system does not vary.

Therefore, the established supporting systems in different subzones can adapt to the deformation characteristics of the roof in different subzones. On the premise of playing 


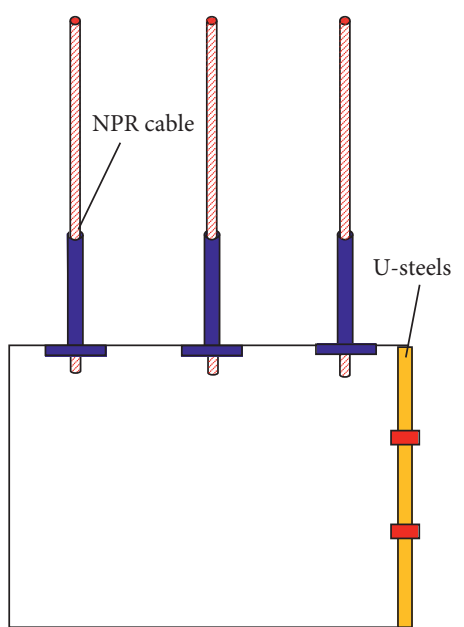

(a)

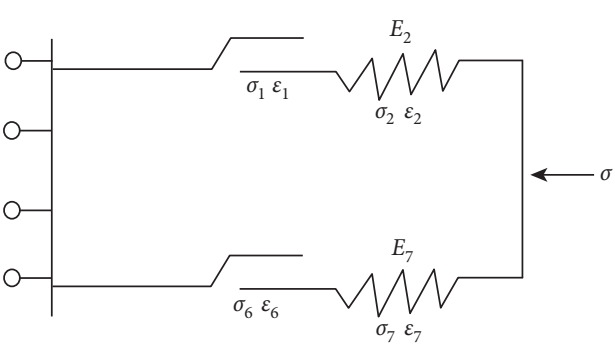

(b)

Figure 18: The constitutive model of the supporting system for the stable zone of the retained roadway.

the strongest supporting role in the system, they are able to realise yielding under constant resistance and guarantee controllable deformation of the roof, thus finally ensuring the stability of the retained roadway.

4.4. Engineering Test Effect. The convergence between the roadway roof and floor and the stress on single props during entry retaining are monitored, as shown in Figures 19 and 20: the deformation of the roadway roof and floor is mainly between 0 and $150 \mathrm{~m}$ behind the working face. Within the first $55 \mathrm{~m}$, the roof and floor move faster, where the roof subsidence reaches $47 \mathrm{~mm}$, accounting for $61 \%$ of the total deformation; the convergence between the roof and floor is $147 \mathrm{~mm}$, which accounts for $57 \%$ of the total deformation; in the range of 55 to $150 \mathrm{~m}$ behind the working face, movement of the roadway roof decelerates and gradually stabilises beyond $150 \mathrm{~m}$. Eventually, the roof subsidence, floor heave, and convergence between the roadway roof and floor reach 77,180 , and $257 \mathrm{~mm}$, respectively.

According to the change in the stress on each single prop, it can be seen that the whole entry-retaining process can be divided into three stages: (I) Pressure-growth stage: in the range of 0 to $20 \mathrm{~m}$ behind the working face, the pressure on each single prop constantly increases. In this stage, single props have not reached their rated working resistance, and the support resistance linearly rises with increasing roof subsidence. (II) Yielding stage under constant pressure: in the range of 20 to $150 \mathrm{~m}$ behind the working face, the deformation and rate of deformation of the roof are large, and therefore the support resistance of single props increases rapidly during compression due to a failure to leak liquid timeously via the pressure-relief valves. Thus, the resistance is found to fluctuate. (III) Stable stage: beyond $150 \mathrm{~m}$ behind the working face, the roof no longer subsides, and the pressure on each single prop gradually stabilises. This indicates that the broken rock has been able to provide stable support to the overlying strata of the main roof. In this case, single props can be progressively withdrawn, leaving only the anchor bolts (cables) and the sliding-type gangue-retaining structure formed by $\mathrm{U}$-shaped steel members in the roadway to support the roof.

By comprehensively analysing the deformation characteristics of the roadway and the stress characteristics of single props, the supporting system is seen to undergo three stages, i.e., pressure growth, yielding under constant resistance, and then stabilisation, under the influence of the roof movement during entry retention. It can adapt to the deformation characteristics and satisfy the demand for support to the roof of the retained roadway. After withdrawing the single props (Figure 21), the final convergence between the roof and floor of the roadway reaches $257 \mathrm{~mm}$, showing a favourable effect of entry retention.

\section{Discussion}

5.1. The Structural Model and Mechanical Characteristics of Surrounding Rocks of the Retained Roadway. A simplified mechanical model of the surrounding rock structure in different subzones of the retained roadway formed by roof cutting in an inclined coal seam was established; the formulae predicting the support resistance in the roadway were attained; this was used to calculate the characteristics of the roof deformation and the support requirements in the roadway under the influence of the dip angle of the coal seam. This is different from previous studies of horizontal coal seams [10-16]. However, the influence of mining dynamic pressure was not reflected in the formula; the influence of mining dynamic pressure should be fully considered in the construction of support system.

Due to the influence of the advanced dynamic pressure generated during mining, the roof of the advanced zone of the retained roadway is necessary to increase the support strength in the roadway to resist the advanced dynamic pressure. The roof in the dynamic pressure area of the retained roadway can be regarded as a cantilever beam with one end supported by coal and the other end suspended. Influenced by overburden strata movement 


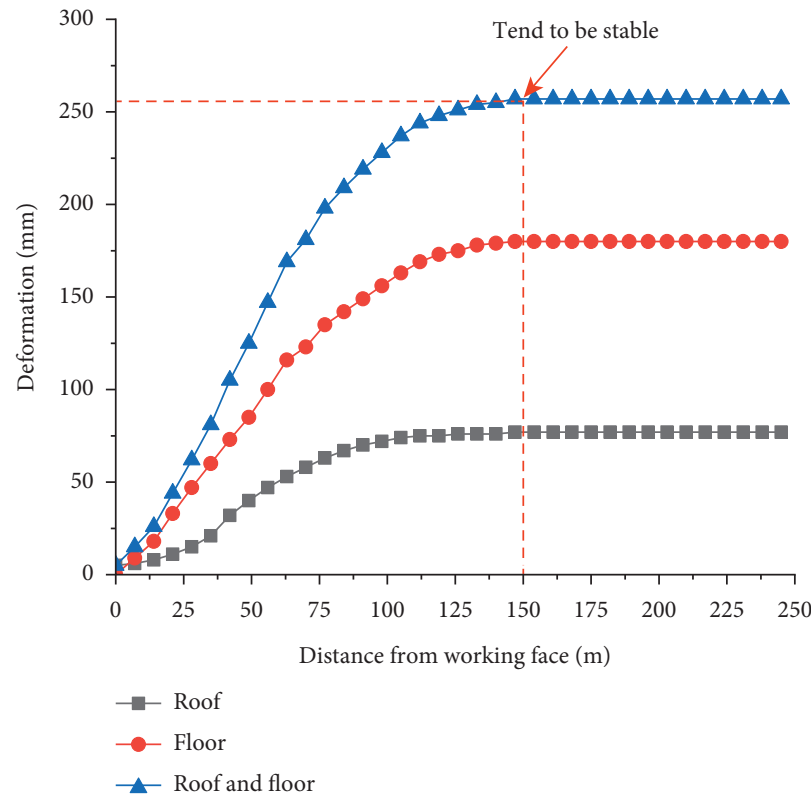

(a)

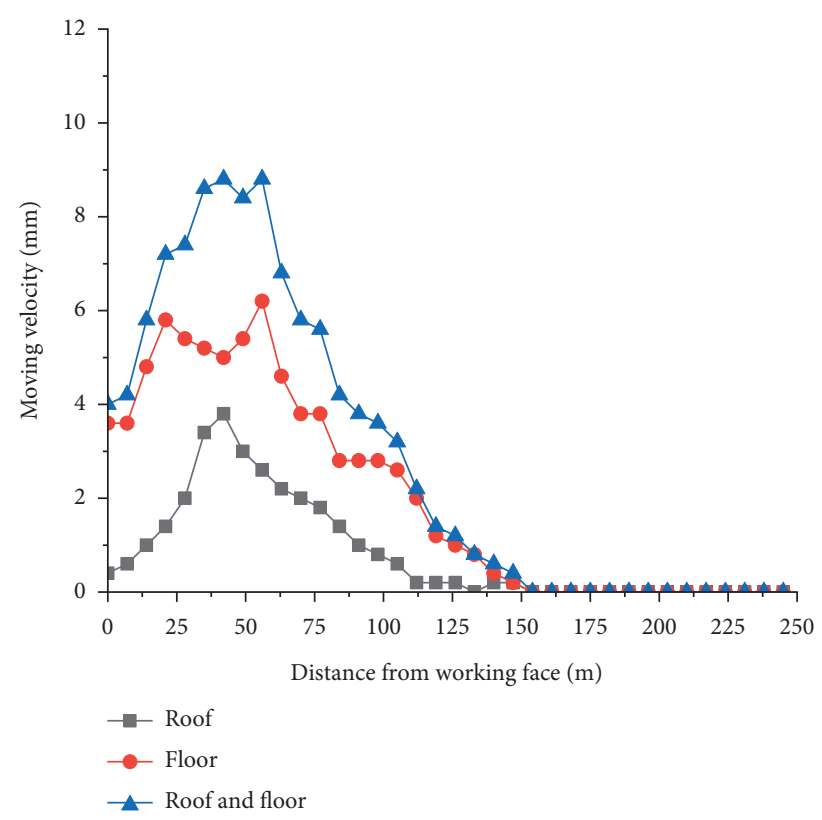

(b)

FIGURE 19: Convergence of the roadway roof and floor at typical monitoring points: (a) deformation of roof and floor; (b) moving velocity of roof and floor.

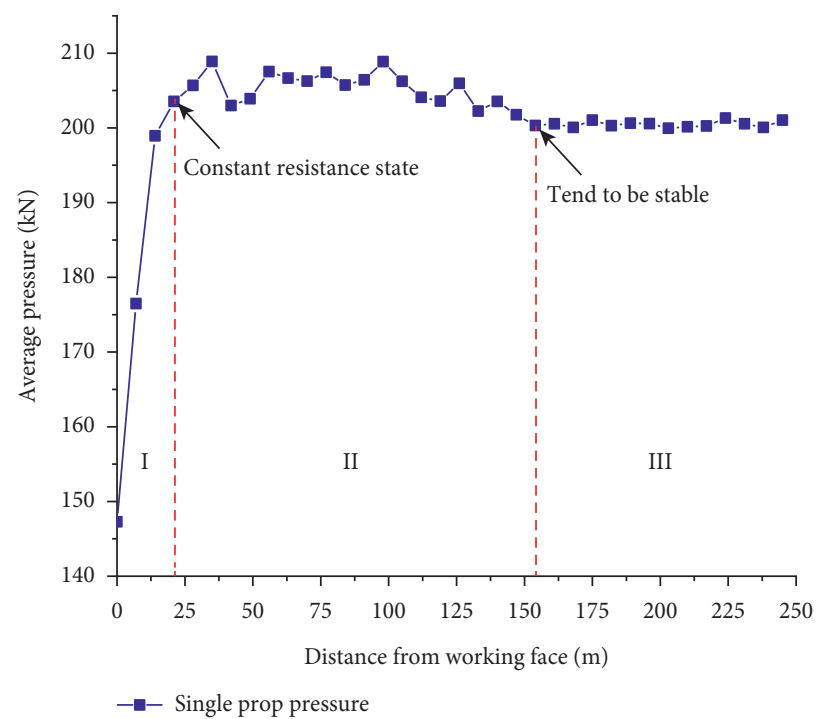

FIGURE 20: The changes in the pressure on single props.

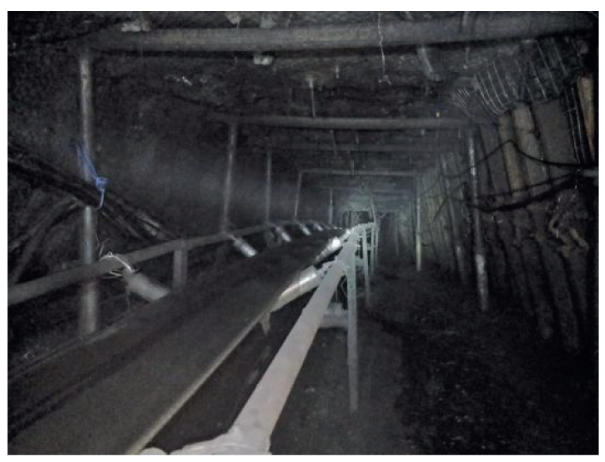

Figure 21: The effect of entry retention. 
and caving of gangues, the roof subsides. In this case, the support resistance required in the zone is maximised. The roof in the stable zone of the retained roadway can be taken as a simply supported beam, with one end supported by coal and the other end supported by gangues. The influence of the mining-induced dynamic pressure vanishes: in this condition, it is feasible to weaken the support resistance in the zone and maintain roadway stability by relying on coal and broken gangues.

\subsection{Deformation Characteristics of the Roof during Entry} Retention by Roof Cutting. We have obtained the deformation characteristics of the roadway roof under the conditions of roof cutting and without roof cutting. Through comparative analysis, it is found that when relieving the pressure by roof cutting, the roadway roof gradually stabilises after 2000 loading steps, suggesting that the gangues in the goaf have been compacted; in this context, the roadway roof is synchronously supported by the coal sides and gangues in the goaf and eventually tends to stabilise; without pressure relief by roof cutting, gangues fail to provide the effective support force for the roadway roof and its overlying strata owing to their caving over a certain height. As a result, the roadway roof suffers significant subsidence and then collapses. It can be found that, given a sufficient height when cutting the roof, the key to realising self-stabilisation of the roadway is that the support in the roadway can guarantee a controllable rotation and subsidence of the roof to acquire support from gangues.

\subsection{Deformation Characteristics of the Roof-Support System in} Different Subzones. According to mechanical characteristics of supporting materials, the rheological mechanical models and constitutive equations of supporting systems for roadways in different subzones were established for the first time.

We found that the roof in the advanced zone of the retained roadway is slowly deformed. In this condition, the support resistance provided by the supporting system rises with the increased deformation of the roof, thus inhibiting roof subsidence. This is because the NPR cable has not reached the constant resistance, and the single props have not reached the rated working resistance; the support force delivered by the supporting system is mainly provided through the elastic deformation of the steel strands of the NPR cables and single props.

The roof in the dynamic pressure area of the retained roadway is significantly deformed. The supporting system can keep the resistance constant after resistances of various support units all reach a maximum, thus realising collaborative deformation with the roof. This is because the support units have reached their maximum support resistance, the NPR cables realise yielding by slip of the constantresistance device, and the single props realise yielding by leakage of liquid through the safety valve. Thus, the roadway roof and its overlying strata are controlled in their descent to contact with gangues.
As for the stable zone of the retained roadway, the supporting system is no longer deformed. This is because the main pressure on the roof has been transferred to gangues in the goaf, on the premise of a constant support resistance, and the support system works in tandem with the gangues to ensure the stability of the roadway roof.

5.4. Advantages and Limitations. The technique overcomes the waste of resources induced by the retention and abandonment of the supporting coal pillars, and it has been widely used in near-horizontal, thin, medium-thick, and thick coal seams $[10,11,36,37]$. In this study, the technique of roadway retention using roof cutting was successfully applied in an inclined coal seam, thus addressing the problem of the waste of resource during mining and providing guidance for future projects relying on roadway retention formed by roof cutting under similar geological conditions.

It should be pointed out that this study did not fully consider the influences of coal seam thickness and lithological changes in the roof on the retained roadway formed by roof cutting in inclined coal seams. In future studies, research into roadway retention by roof cutting in coal seams of different thickness and under different roof conditions should be conducted.

\section{Conclusions}

By exploring the structural evolution of the deformation of the rock surrounding a retained roadway formed by roof cutting in inclined coal seams, support systems for the roof in different subzones of the retained roadway were established and applied in practice. The following conclusions are drawn:

(1) The mechanical models for surrounding rock structures in the advanced zone, dynamic pressure area, and stable zone of the retained roadway formed by roof cutting in inclined coal seams were separately established. On this basis, the deformation of the roof in the corresponding subzones and formulae predicting the support resistance in the roadway were attained. These provide a theoretical basis for the parameter design of the retained roadway by roof cutting in inclined coal seams.

(2) The results obtained through numerical simulation show that the roof of the retained roadway by roof cutting tends to stabilise after subsiding by some $0.55 \mathrm{~m}$ in the entry-retaining process; the roadway roof without roof cutting always subsides and is deformed. This implies that the roof of the retained roadway formed by roof cutting can be effectively supported by gangues in the goaf after subsiding by a certain distance, thus realising self-stabilisation of the roadway.

(3) Aiming at the stress characteristics of different subzones and mechanical characteristics of the selfstabilisation of the roadway, the supporting systems 
in corresponding subzones were established by applying NPR cables, single props, and a sliding-type gangue-retaining structure formed using U-shaped steel members. Furthermore, three rheological mechanical models (S-N-S, S-N-S-S, and S-S) corresponding to the support systems and their constitutive equations were proposed.

(4) The working principles of the support systems in different subzones were analysed from the perspective of rheological mechanics. The results show that the established supporting systems can realise yielding under constant resistance on the premise of providing the maximum support resistance among various units. Furthermore, the roof pressure is slowly transferred to gangues in the goaf, thus finally realising the controlled stabilisation of the roadway.

(5) The results obtained through in situ testing and measurement indicate that the supporting system is best placed in the pressure-growth stage of the gobside entry-retention process within the first $20 \mathrm{~m}$ behind the working face; the system mainly realises yielding under constant pressure in the range of 20 to $150 \mathrm{~m}$ behind the working face; the roof tends to stabilise beyond $150 \mathrm{~m}$ behind the working face. The final convergence between the roof and floor of the roadway reaches $257 \mathrm{~mm}$, showing a favourable entry-retention effect.

\section{Data Availability}

The data used to support the findings of this study are available from the corresponding author upon request.

\section{Conflicts of Interest}

The authors declare that there are no conflicts of interest regarding the publication of this paper.

\section{Acknowledgments}

This research was funded by the National Natural Science Foundation of China (no. 52074300); Science and Technology Department Joint Fund Project of Guizhou Province, China (no. LH[2017]7036); and Youth Science and Technology Talent Growth Project of Guizhou Provincial Department of Education (no. ky[2018]414).

\section{References}

[1] R. C. Milici, R. M. Flores, and G. D. Stricker, "Coal resources, reserves and peak coal production in the United States," International Journal of Coal Geology, vol. 113, pp. 109-115, 2013.

[2] A. M. Lechner, O. Kassulke, and C. Unger, "Spatial assessment of open cut coal mining progressive rehabilitation to support the monitoring of rehabilitation liabilities," Resources Policy, vol. 50, pp. 234-243, 2016.

[3] J. Yuan, "The future of coal in China," Resources, Conservation and Recycling, vol. 129, pp. 290-292, 2018.
[4] S. Kimura and H. Phoumin, Energy Outlook and Energy Saving Potential in East Asia 2019, Economic Research Institute for ASEAN and East Asia, Jakarta, Indonesia, 2019.

[5] H. Wu, "Research on asymmetrical deformation laws and stability control of deep inclined rock strata roadway," Doctoral Dissertation, China University of Mining and Technology, Xuzhou, China, 2014.

[6] S. S. Peng and H. Chiang, Longwall Mining, Wiley, Hoboken, NJ, U.S.A, 1984.

[7] H. Wang, Y. Jiang, Y. Zhao, J. Zhu, and S. Liu, "Numerical investigation of the dynamic mechanical state of a coal pillar during longwall mining panel extraction," Rock Mechanics and Rock Engineering, vol. 46, no. 5, pp. 1211-1221, 2013.

[8] Y. J. Wang, M. C. He, K. X. Zhang et al., "Strata behavior characteristics and control countermeasures for the gateroad surroundings in innovative non-pillar mining method with gateroad formed automatically," Journal of Mining and Safety Engineering, vol. 35, no. 4, pp. 677-685, 2018.

[9] M. C. He, S. Y. Chen, Z. B. Guo et al., "Control of surrounding rock structure for gob-side entry retaining by cutting roof to release pressure and its engineering application," Journal of China University of Mining and Technology, vol. 46, no. 4, pp. 968-979, 2017.

[10] X. G. Ma, M. C. He, J. Wang et al., "Mine strata pressure characteristics and mechanisms in gob-side entry retention by roof cutting under medium-thick coal seam and compound roof condition," Energies, vol. 11, pp. 1-25, 2018.

[11] M. C. He, Y. B. Gao, J. Yang et al., "An innovative approach for gob-side entry retaining in thick coal seam longwall mining," Energies, vol. 10, no. 11, p. 1785, 2017.

[12] D. Y. Fan, X. S. Liu, Y. L. Tan et al., "Roof cutting parameters design for gob-side entry in deep coal mine: a case study," Energies, vol. 12, no. 10, pp. 1-25, 2019.

[13] D. Fan, X. Liu, Y. Tan, L. Yan, S. Song, and J. Ning, “An innovative approach for gob-side entry retaining in deep coal mines: a case study," Energy Science \& Engineering, vol. 7, no. 6, pp. 2321-2335, 2019.

[14] C. L. Han, N. Zhang, B. Y. Li, G. Y. Si, and X. G. Zheng, "Pressure relief and structure stability mechanism of hard roof for gob-side entry retaining," Journal of Central South University, vol. 22, no. 11, pp. 4445-4455, 2015.

[15] J. G. Guo, Y. H. Li, and F. L. He, "Study on stability control of retained gob-side entry by blasting fracturing roof technology in thick immediate roof," Shock and Vibration, vol. 2021, Article ID 6613562, 12 pages, 2021.

[16] X. M. Sun, Y. Y. Liu, J. W. Wang et al., "Study on threedimensional stress field of gob-side entry retaining by roof cutting without pillar under near-group coal seam mining," Processes, vol. 7, no. 9, p. 552, 2019.

[17] Y. Zhang, H. C. Xu, P. Song et al., "Stress evolution law of surrounding rock with gob-side entry retaining by roof cutting and pressure release in composite roof," Advances in Materials Science and Engineering, vol. 2020, Article ID 1961680, 15 pages, 2020.

[18] J. G. Ning, J. Wang, T. T. Bu et al., "An innovative support structure for gob-side entry retention in steep coal seam mining," Minerals, vol. 7, no. 5, p. 75, 2017.

[19] Z. W. Du, S. J. Chen, J. B. Ma et al., "Gob-side entry retaining involving bag filling material for support wall construction," Sustainability, vol. 12, no. 16, p. 6353, 2020.

[20] S. Yan, T. X. Liu, J. B. Bai et al., "Key parameters of gob-side entry retaining in A gassy and thin coal seam with hard roof," Processes, vol. 6, no. 5, p. 51, 2018. 
[21] H. J. Luan, Y. J. Jiang, L. J. Zhou et al., "Stability control and quick retaining technology of gob-side entry: a case study," Advances in Civil Engineering, vol. 2018, Article ID 735732, 13 pages, 2018.

[22] J. K. Wu, Y. Dong, J. R. Chen et al., "Short cantilever rock beam structure and mechanism of gob-side entry retaining roof in reuse period," Shock and Vibration, vol. 2020, Article ID 8835820, 14 pages, 2020.

[23] X. Y. Zhang, M. C. He, J. Yang Jun et al., "An innovative nonpillar coal-mining technology with automatically formed entry: a case study," Engineering, vol. 6, pp. 1315-1329, 2020.

[24] Q. X. Meng, W. Y. Xu, H. L. Wang et al., "DigiSim-an open source software package for heterogeneous material modeling based on digital image processing," Advances in Engineering Software, vol. 148, Article ID 102836, 2020.

[25] Q. Yin, J. Y. Wu, C. Zhu et al., "Shear mechanical responses of sandstone exposed to high temperature under constant normal stiffness boundary conditions," Geomechanics and Geophysics for Geo-Energy and Geo-Resources, vol. 7, no. 2, Article ID 35, 2021.

[26] C. Zhu, M. C. He, M. Karakus, X. H. Zhang, and Z. Guo, "The collision experiment between rolling stones of different shapes and protective cushion in open-pit mines," Journal of Mountain Science, vol. 18, no. 5, pp. 1391-1403, 2021.

[27] A. Li, F. Dai, Y. Liu et al., "Dynamic stability evaluation of underground cavern sidewalls against flexural toppling considering excavation-induced damage," Tunnelling and Underground Space Technology incorporating Trenchless Technology Research, vol. 112, Article ID 103903, 2021.

[28] Q. Wang, H. K. Gao, B. Jiang et al., "In-situ test and boltgrouting design evaluation method of underground engineering based on digital drilling," International Journal of Rock Mechanics and Mining Sciences, vol. 138, Article ID 104575, 2021.

[29] Q. Wang, Z. H. Jiang, B. Jiang et al., "Research on an automatic roadway formation method in deep mining areas by roof cutting with high-strength bolt-grouting," International Journal of Rock Mechanics and Mining Sciences, vol. 128, Article ID 104264, 2020.

[30] Z. G. Tao, C. Zhu, M. C. He et al., “A physical modeling-based study on the control mechanisms of Negative Poisson's ratio anchor cable on the stratified toppling deformation of antiinclined slopes," International Journal of Rock Mechanics and Mining Sciences, vol. 138, Article ID 104632, 2021.

[31] C. Zhu, M. He, M. Karakus, X. Zhang, and Z. Tao, "Numerical simulations of the failure process of anaclinal slope physical model and control mechanism of negative Poisson's ratio cable," Bulletin of Engineering Geology and the Environment, vol. 80, no. 4, pp. 3365-3380, 2021.

[32] Y. F. Li, X. Z. Hua, R. C. Cai et al., "Mechanics analysis on the stability of key block in the gob-side entry retaining and engineering application," Journal of Mining and Safety Engineering, vol. 29, no. 3, pp. 357-364, 2012.

[33] C. J. Hou and N. J. Ma, "Stressin in-seam roadway sides and limit equilibrium zone," Journal of China Coal Society, vol. 14, no. 4, pp. 21-29, 1989.

[34] Z. G. Tao, C. Zhu, M. C. He et al., "Research on the safe mining depth of anti-dip bedding slope in Changshanhao Mine," Geomechanics and Geophysics for Geo-Energy and GeoResources, vol. 6, p. 36, 2020.

[35] Y. Wang, W. K. Feng, R. L. Hu et al., "Fracture evolution and energy characteristics during marble failure under triaxial fatigue cyclic and confining pressure unloading (FC-CPU) conditions," Rock Mechanics and Rock Engineering, vol. 54, pp. 799-818, 2020.

[36] H. P. Xie, Y. L. Liu, D. C. Ai et al., "Study on technology of cut top and relief pressure without coal pillar at gob-side entry retaining of thin coal seam," Coal technology, vol. 36, no. 5, pp. 36-38, 2017.

[37] Z. B. Guo, J. Wang, T. P. Cao et al., "Research on key parameters of gob-side entry retaining automatically formed by roof cutting and pressure release in thin coal sean mining," Journal of China University of Mining and Technology, vol. 45, no. 5, pp. 879-885, 2016. 